\title{
Response of Bolivian gray titi monkeys (Plecturocebus donacophilus) to an anthropogenic noise gradient: Behavioral and hormonal correlates
}

\author{
Lucero M Hernani Lineros ${ }^{\text {Equal first author, } 1,2 \text {, Amélie Chimènes }}{ }^{3}$, Audrey Maille ${ }^{3}$, Kimberly Dingess ${ }^{4}$, Damián I Rumiz ${ }^{1,5}$ \\ , Patrice Adret ${ }^{\text {Corresp. Equal first author, } 1}$ \\ ${ }^{1}$ Zoología Vertebrados, Museo de Historia Natural Noel Kempff Mercado, Santa Cruz de la Sierra, Bolivia \\ 2 Carrera de Biología, Universidad Mayor de San Andrés, La Paz, Bolivia \\ 3 Unité Eco-anthropologie UMR 7206, Museum National d'Histoire Naturelle, CNRS, Université de Paris, Paris, France \\ 4 Marshall University, Huntington, West Virginia, United States \\ 5 Fundación Simón I. Patiño, Santa Cruz de la Sierra, Bolivia \\ Corresponding Author: Patrice Adret \\ Email address: padret@museonoelkempff.org
}

Worldwide urban expansion and deforestation have caused a rapid decline of non-human primates in recent decades. Yet, little is known to what extent these animals can tolerate anthropogenic noise arising from roadway traffic and human presence in their habitat. We studied six family groups of titis residing at increasing distances from a busy highway, in a park promoting ecotourism near Santa Cruz de la Sierra, Bolivia. We mapped group movements, sampled the titis' behavior, collected fecal samples from each study group and conducted experiments in which we used a mannequin simulating a human intrusion in their home range. We hypothesized that groups of titi monkeys exposed to higher levels of anthropogenic noise and human presence would react weakly to the mannequin and show higher concentrations of fecal cortisol compared with groups in least perturbed areas. Sound pressure measurements and systematic monitoring of soundscape inside the titis' home ranges confirmed the presence of a noise gradient, best characterized by the root-mean-square (RMS) and median amplitude (M) acoustic indices; importantly, both anthropogenic noise and human presence co-varied. Study groups resided in small, overlapping home ranges and they spent most of their time resting and preferentially used the lower forest stratum for traveling and the higher levels for foraging. Focal sampling analysis revealed that the time spent moving by adult pairs was inversely correlated with noise, the behavioral change occurring within a gradient of minimum sound pressures ranging from $44 \mathrm{~dB}(\mathrm{~A})$ to $52 \mathrm{~dB}(\mathrm{~A})$. Validated enzyme-immunoassays of fecal samples however detected surprisingly low cortisol concentrations, unrelated to the changes observed in the RMS and M indices. Finally, titis' response to the mannequin varied according to our expectation, with alarm calling being greater in distant groups relative to 
highway. Our study thus indicates reduced alarm calling through habituation to human presence and suggests a titis' resilience to anthropogenic noise with little evidence of physiological stress. 
1 Response of Bolivian gray titi monkeys (Plecturocebus donacophilus) to an anthropogenic noise 2 gradient: behavioral and hormonal correlates.

3

4 Lucero M. Hernani Lineros ${ }^{1,2}$, Amélie Chimènes ${ }^{3}$, Audrey Maille ${ }^{3}$, Kimberly A. Dingess ${ }^{4}$, 5 Damián Rumiz ${ }^{1,5}$ \& Patrice Adret ${ }^{1}$ *

6

7

$8 \quad{ }^{1}$ Museo de Historia Natural Noel Kempff Mercado, Santa Cruz de la Sierra, Bolivia

$9 \quad{ }^{2}$ Universidad Mayor de San Andrés, La Paz, Bolivia

10 3 Unité Eco-anthropologie UMR 7206, Museum National d'Histoire Naturelle, CNRS, Université de

11 Paris, Paris, France

$12{ }^{4}$ Marshall University, West Virginia, USA

$13{ }^{5}$ Fundación Simón I. Patiño, Santa Cruz de la Sierra, Bolivia

19 Correspondence:

20 Patrice Adret ${ }^{1}$,

2187 rue de la Marcellière,

22 Les Sables d'Olonne 85100, France

23 Email: patrice.adret@gmail.com 


\section{ABSTRACT}

25 Worldwide urban expansion and deforestation have caused a rapid decline of non-human primates in 26 recent decades. Yet, little is known to what extent these animals can tolerate anthropogenic noise 27 arising from roadway traffic and human presence in their habitat. We studied six family groups of 28 titis residing at increasing distances from a busy highway, in a park promoting ecotourism near 29 Santa Cruz de la Sierra, Bolivia. We mapped group movements, sampled the titis' behavior, collected fecal samples from each study group and conducted experiments in which we used a mannequin simulating a human intrusion in their home range. We hypothesized that groups of titi monkeys exposed to higher levels of anthropogenic noise and human presence would react weakly to the mannequin and show higher concentrations of fecal cortisol compared with groups in least perturbed areas. Sound pressure measurements and systematic monitoring of soundscape inside the titis' home ranges confirmed the presence of a noise gradient, best characterized by the root-meansquare (RMS) and median amplitude (M) acoustic indices; importantly, both anthropogenic noise and human presence co-varied. Study groups resided in small, overlapping home ranges and they spent most of their time resting and preferentially used the lower forest stratum for traveling and the higher levels for foraging. Focal sampling analysis revealed that the time spent moving by adult pairs was inversely correlated with noise, the behavioral change occurring within a gradient of minimum sound pressures ranging from $44 \mathrm{~dB}(\mathrm{~A})$ to $52 \mathrm{~dB}(\mathrm{~A})$. Validated enzyme-immunoassays of fecal samples however detected surprisingly low cortisol concentrations, unrelated to the changes observed in the RMS and M indices. Finally, titis' response to the mannequin varied according to our expectation, with alarm calling being greater in distant groups relative to highway. Our study thus indicates reduced alarm calling through habituation to human presence and suggests a titis' resilience to anthropogenic noise with little evidence of physiological stress. 


\section{INTRODUCTION}

48 Owing to the constant expansion of cities and deforestation around the world, humans have

49 increasingly invaded wildlife habitats, reshaping the landscape into man-altered ecosystems

50 (Hendry, Gotanda \& Svensson, 2017). Although urban habitats may provide benefits to city-

51 dwelling animals, such as greater food availability and less exposure to natural predators (Muhly et

52 al., 2011; Adams, 2016), anthropogenic disturbances often have detrimental consequences on

53 wildlife (Ciuti et al., 2012; Hendry, Gotanda \& Svensson, 2017; Palacios, D’Amico \& Bertellotti,

54 2018), which has given rise to a field of research known as "urban wildlife ecology" that aims to

55 understand the effects of human disturbance on animal populations that live within the cities or close

56 to human settlements (Gill, Sutherland \& Watkinson, 1996; Frid \& Dill, 2002; Soulsbury \& White,

57 2015; Gaynor et al. 2018).

For many organisms, an omnipresent source of stress is represented by anthropogenic sound

59 (Slabbekoorn et al., 2018; Kunc \& Schmidt, 2019; Raboin \& Elias, 2019), also called

60

61

62

63

64

65

66

67

68

69

anthropophony (Pijanowski et al., 2011). Anthropophony is closely associated with human activity

routine, from construction and mass recreation to transportation (aerial, terrestrial and marine), the

latter being considered as one of the most pervasive acoustic perturbations on Earth (Barber, Crooks

\& Fritsrup, 2010; Shannon et al., 2016). Anthropophony can alter the behavior, phenotype and

homeostasis of animals living near or within the cities, with potential effects at a population level

(McGregor et al., 2013; Giraudeau et al., 2014). Indeed, noise pollution has a dramatic impact on

habitat selection, foraging patterns and communication networks of animals (anurans: Bee \&

Swanson, 2007; Grace \& Noss, 2018; birds: Swaddle \& Page, 2007; terrestrial mammals: Shannon

et al., 2014; marine mammals: Nowacek et al., 2007; McMullen, Schmidt \& Kunc, 2014) with

serious implications for their survival and reproduction (reviewed in Brumm \& Slabbekoorn, 2005;

Peer) reviewing PDF | (2020:06:49834:1:2:NEW 15 Oct 2020) 
70 Blickley \& Patricelli, 2010; Brumm, 2013; McGregor et al., 2013). Collateral nociceptive effects

71 induced by noise include hearing impairments, cardiovascular defects, surge in glucocorticoid

72 secretion, sleep and immune system disorders, and may also compromise DNA integrity and gene

73 expression (Kight \& Swaddle, 2011; Slabbekoorn et al., 2018).

74 To mitigate or counteract the stress incurred by anthropogenic noise, animals can generate

75 different responses: fleeing as a result of fear (Laundré, Hernández \& Ripple, 2010), showing

76 awareness of the source of noise via increased vigilance (Frid \& Dill, 2002; Barber, Crooks \&

77 Fritsrup, 2010) or coping with the disturbance through habituation (Walker, Dee Boersma \&

78 Wingfield, 2005). In the process, many species have been shown to exhibit vocal flexibility, such as

79 amplitude and frequency shift, in order to avoid signal masking (reviewed in Brumm \&

80 Slabbekoorn, 2005; Brumm, 2013; McGregor et al., 2013; Slabbekoorn et al., 2018; but see

81 Zollinger et al., 2018). Noise tolerance is species-specific and depends more on the animals' sensory

82 capacities and decision-making than on the intensity of sound per se (reviewed in Saunders \&

83 Dooling, 2018).

Growing concerns of the harmful impact of chronic anthropogenic noise on wildlife behavior and physiology have prompted researchers to investigate the effect of noise pollution in Neotropical primates, such as Atelidae (spider monkeys, Ateles spp.: Rangel-Negrín et al., 2009; Rimbach et al.,

87 2013; Vanlangendonck et al., 2015; howler monkeys, Alouatta spp.: Martínez-Mota et al., 2007;

88 Behie, Pavelka \& Chapman, 2010; Rimbach et al. 2013; Vanlangendonck et al., 2015; Cantarelli et 89 al., 2017), Pitheciidae (titi monkeys, Callicebus nigrifrons: Duarte et al., 2017) and Callithrichidae 90 (marmosets, Callithrix penicillata: Duarte et al., 2011; Santos et al., 2017; tamarins, Saguinus

91 leucopus: Soto-Calderón, Álvarez-Cardona \& García-Montoya, 2016). For example, black-tufted 
92 marmosets (C. penicillata) have been shown to avoid noisy areas of an urban park, irrespective of

93 food availability (Duarte et al., 2011).

94 In a comprehensive review of the effects of anthropogenic noise on wildlife, Shannon and

95 colleagues (2016) provide several important recommendations, one of which is to measure the

96 animals' responses over a gradient of noise levels. Indeed, heavy traffic noise on major highways of

97 city outskirts gives rise to a noticeable acoustic gradient in the landscape. Primates - and other

98 animals - roaming in the remnant forests along these roads are thus exposed to varying levels of

99 anthropogenic noise, depending on the distance of their home range from the road. This, in turn,

100 may affect the monkeys' behavior and homeostasis (Sapolsky, Romero \& Munck, 2000).

101 To evaluate the impact of an anthropogenic noise gradient on the behavior and physiology

102 of a peri-urban population of titi monkeys (Pitheciidae; sub-family Callicebinae), we conducted a

103 study integrating acoustics, ethology and non-invasive stress endocrinology in one suite. We

104 hypothesized that family groups residing in areas with greater exposure to anthropophony will differ

105 both behaviorally (higher tolerance of humans) and physiologically (elevated glucocorticoids) from

106 groups least exposed to anthropophony.

107

108 MATERIALS \& METHODS

109 Study area

110 The study was conducted in the Ecological Park of Yvaga Guazú (S14¹4’30”, W6658’39”), 13 km

111 from downtown Santa Cruz de la Sierra (Fig. 1A). This privately-owned property of 15 ha is home

112 to a small, but thriving population of Bolivian gray titi monkeys ( $P$. donacophilus; Wallace et al,

113 2018) that share the area with several groups of Azara's owl monkeys (Aotus azarae) and squirrel

114 monkeys (Saimiri boliviensis). The park is surrounded to the north by a busy highway and to the 
115 south by the quiet suburb of Campo Verde. The northern section of the park, where human presence

116 abounds, consists of a cultivated garden that exhibits both native and exotic plants to promote

117 ecotourism. Further south, the garden gives way to a remnant of Chiquitano dry forest $(\sim 7$ ha),

118 including species such as Ceiba speciosa, Cedrela odorata, Enterolobium contortisiliquum,

119 Zeyheria tuberculosa, Samanea tubulosa, Albizia niopoides, Swietenia macrophylla and Ficus sp.

120 with an abundant understory of Piperacae shrubs. Some twenty employees work in the park on a

121 daily basis (8:00-18:00 h), assuming various functions such as gardening, horticulture and general

122 maintenance. There are also guided tours for visitors and occasional social events. To account for

123 the various sources of anthropogenic disturbance (Table 1), we subdivided the study area into three

124 sectors characterized by high, moderate and low levels of human presence (Fig. 1B).

125

126 Study animals

127 The six study groups consisted of a pair-bonded adult male and female with their putative offspring

128 (4-6 individuals/group). Groups were labeled according to the distance between their home range

129 and the highway. We used the northernmost limit of each home range as a measure of the groups'

130 respective distance to the highway. Groups 1 and 2 resided in the cultivated garden where human

131 presence culminated on a daily basis. Groups 3 and 4 resided mid-way across the park where human

132 presence was moderate. Notably, group 3 occupied an area that overlapped an adjacent property on

133 the west side of the park. Groups 5 and 6 resided in the native forest, which was least exposed to

134 human presence. During a two-week-period preceding data collection, LHL set out to individually

135 recognize the animals, based on their physical appearance, such as body size, age class, coat color

136 pattern and facial characteristics. The putative offspring of all study groups consisted of an infant

137 and juvenile, but some of the groups differed by the presence of a sub-adult (G2, G6) and un- 
138 weaned infants (G3, G4, G6; Table 2). To assess the age class of animals, we relied on the criteria

139 established by other authors (de Luna et al., 2010; Cäsar et al., 2012).

140

\section{Data collection}

142 Acoustic survey methods We used two different procedures to investigate the noise gradient in

143 the study area. We began by measuring sound pressure levels (SPL) over a two-month period, and

144 later we sampled the soundscape using passive acoustic monitoring (PAM) over a six-month period.

145 While the first approach is based on direct measures of loudness, the second approach allows

146 identifying which acoustic features best describe the noise gradient.

148 SPL Sound pressure was measured with a calibrated sound level meter (Voltcraft Plus SL-300), 149 mounted on a tripod at $\sim 1.50 \mathrm{~m}$ above ground. On the basis of similar studies (Díaz et al., 2011; 150 Duarte et al., 2011), we elected the A-weighting filter, which approximates the sensitivity of the

151 human ear $(0.02-17.0 \mathrm{kHz})$. A-weighting, however, dampens low frequency noise, thus minimizing

152 the true levels which would have been obtained with flat weighting (also called Z-weighting). The

153 grid layout $(180 \times 800 \mathrm{~m})$ consisted of three parallel transects roughly perpendicular to the highway

154 and located on the east side, in the middle and on the west side of the park (Fig. 1C). Each transect

155 comprised nine recording stations at $\sim 100 \mathrm{~m}$ intervals thus resulting in 27 stations, all marked and

156 geo-referenced (Garmin Etrex 30). At each station, we noted the maximum and minimum SPL

157 values ('extreme values' hereafter) displayed on the instrument, after one minute of continuous

158 recording with the sensor oriented towards the highway, and again with the sensor oriented towards

159 Campo Verde. This was done to control for the directionality of the noise gradient. On a given day,

160 the nine stations along a transect were sampled five times by one researcher (PA), at an interval of 
161 three hours starting at 6:00, 9:00, 12:00, 15:00 and 18:00 h. Three sampling days were necessary to

162 cover the entire grid. This procedure was repeated on nine sampling days thus resulting in a total of

1631620 measures, with 15 pseudo-replications at each recording station (9 stations $\times 2$ values x 2

164 orientations x 5 sampling hours x 9 sampling days).

165

166 PAM Passive acoustic monitoring was performed sequentially at 27 recording stations, all geo167 referenced within the park (Fig. 2A). Soundscape data were acquired with a single H4n recorder 168 (Zoom Corporation, Japan) connected to an Arduino UNO timer via the 5V input of the recorder.

169 The ZOOM H4n was powered by a charger (Solar DC System XGX1206), which was connected to

170 three $12 \mathrm{~V}$ batteries mounted in parallel. Two photovoltaic solar panels were positioned 0-20 $\mathrm{m}$ from

171 the recording device, in an area with good sun exposure to ensure that the batteries would operate

172 overnight. All recording components were placed in a waterproof plastic box screwed to a metal

173 mount, which was supported by two tripods at a height of $1.50 \mathrm{~m}$. The microphone heads protruded

174 from a small opening in the box and were protected by an anti-wind screen. The autonomous

175 recording unit (ARU) was deployed at four locations within the home range of each study group,

176 according to a rotation schedule over the entire study period, thus yielding 24 recording locations (4

177 locations x 6 groups). The three additional sites near the highway (Fig. 2A) served as a baseline for 178 anthropophony (road traffic) in a reference area called G0.

179 Our rotation schedule consisted in four cycles of recording sessions. For each cycle, only 180 one location per home range was sampled for $\sim 48 \mathrm{~h}$ on average before moving to the next location, 181 i.e. sequentially across groups. We rotated the recording unit every $5.0 \pm 2.9$ days (mean $\pm \mathrm{sd}$ ),

182 which includes the time $(>24 \mathrm{~h})$ necessary to recharge the batteries after a recording session. PAM 183 started at 18:00 $\mathrm{h}$ with the recording level set to 100 (maximal sensibility). The ARU recorded one 
184 minute of ambient sound every $10 \mathrm{~min}$ for a minimum of $24 \mathrm{~h}$. The sampling rate was $44,100 \mathrm{~Hz}$

185 with a 16-bit depth. The "mono mix" function of the Zoom H4n recorder was selected to mix the left

186 and right channels. This recording schedule yielded 144 one-minute sound files per $24 \mathrm{~h}$, which

187 were saved in WAV format on a 32GB Secure Digital memory card.

188

Because the sound was identical on both channels, only the left channel was analyzed using

the Seewave package (Sueur, Aubin \& Simonis, 2008) available in the R environment (v.3.6.1, R

190

Development Core Team, 2017). Moreover, given the variable duration of the recordings (range:

191

24-65 h), we analyzed only those samples collected during the first 24 hours. For each sample, we

192

computed the values of two acoustic indices, which were developed for rapid biodiversity

193

assessment (Sueur et al., 2014): (1) the root-mean-square (RMS) index and (2) the median amplitude

194

envelope (M) index. The RMS index computes the averaged dispersion of the amplitude values

according to the formula:

196

$\mathrm{RMS}=\frac{\sqrt{x_{1}^{2}+x_{2}^{2}+\ldots+x_{n}^{2}}}{n}$

197

where $" \mathrm{x}_{1} \ldots \mathrm{x}_{\mathrm{n}}$ " corresponds to the amplitude values (positive or negative) of the signal in a given time interval and " $n$ " the number of sound samples. This metric provides a measure of the intensity

of the sound (Rodriguez et al., 2013; Sueur et al., 2014) and has been shown to be positively associated with increasing vocal activity along a gradient of habitat degradation (Eldridge et al.,

201 2018). The M metric, another intensity index, is computed according to:

202

$$
\mathrm{M}=\operatorname{median}(\mathrm{A}(\mathrm{t})) \times 2^{(1-\mathrm{depth})}
$$

where $A(t)$ is the amplitude envelope and depth the digital resolution of the signal (16 bits). The

resulting values are then standardized between 0 and 1 by dividing each one by the maximum value.

205 The $\mathrm{M}$ index was first used to estimate the number of animal vocalizations in a temperate woodland 206 (Depraetere et al., 2012). 


\section{Behavioral observations}

209 From September 26, 2017 till January 16, 2018, activity budgets of family groups were evaluated

210 from 51 days of focal sampling (266 hours total). On the day preceding data acquisition, the

211 observer (LHL) located and followed the focal group until it elected its sleeping tree. The focal

212 group was followed again from that location next day. In the case the observer failed to identify the

213 sleeping tree the day before, then the first morning vocalizations served to locate the focal group. A

214 "session of observations" started from the moment the focal group was found until it was lost. In this

215 case, a new search began until the focal group was found again, thus allowing a second "session of

216 observations".

217 Groups were observed throughout the day, according to a pre-established schedule consisting

218 in acquiring data sequentially from each group on a monthly basis. Each individual in the group was

219 monitored for half an hour, using the focal-animal sampling method (Altmann, 1974). That is, every

220 five minutes, the focal individual was observed for one minute, its activity being assigned to one of

221 five main activities: resting (RE), observing (OB), moving (MO), foraging (FO), and socializing

222 (SO) (for more details, see Table 3). The observer also estimated the distance separating the focal

223 individual to the nearest group member and the location of the focal individual in each of three

224 forest strata (S1: 0-5 m, S2: 5-10 m; S3: 10-15 m). Pentax binoculars, 10 x 50 magnification, were

225 used to observe the titis when animals were distant.

226 The paths of each family group were mapped during focal observations on a satellite image

227 of the study area, which contained numerous landmarks and a network of geo-referenced trails.

228 Subsequently, the tracings were reconstructed in Google Earth Pro and the size of each home range

229 was determined according to the method of the minimum convex polygon (Odum \& Kuenzler, 
230 1955). Group travel speed was computed for each path by dividing the distance traveled by the 231 duration of a session of observations.

232 This observation schedule yielded a total of 2897 behavioral events from which activity

233 budgets were computed. The number of events collected for each group was as follows: G1 (n= 234 391), G2 $(n=503), G 3(n=456), G 4(n=735), G 5(n=446)$, and G6 $(n=366)$. For each group 235 member, we calculated the number of times this individual was engaged in a given activity and the 236 respective frequencies for that activity (calculated by adding up the number of times spent in an 237 activity and then dividing by the sum of all activities collected within the group). These numbers are 238 reported as proportions of time spent by the group in each activity. Similarly, the relative number of 239 records in which the focal individual was observed higher or lower than $5 \mathrm{~m}$ above ground gave us 240 the proportion of time spent by group members in each forest stratum. As mentioned above, we collected data of proximity between a focal individual and its 242 nearest companion. We call such transient association a "social dyad". Note that the number of 243 neighbors can vary from 0 (absence of neighbor referred to as "solo") up to the size of the whole 244 group ("grouping"). To quantify the degree of association between group members, we calculated 245 the respective proportions of solos, social dyads and groupings. For social dyads and groupings, the 246 data were split into two categories. "Tight social dyads" were those where the nearest neighbor was 247 located within a radius of $1 \mathrm{~m}$ from the focal individual and "loose social dyads" were those where 248 the nearest neighbor was located within a radius of 1.5 to $7 \mathrm{~m}$ from the focal individual. We made a 249 similar distinction between "tight groupings" and "loose groupings". We chose this threshold 250 because in each group the vast majority of dyads and groupings were recorded within a $1 \mathrm{~m}$ radius.

\section{Field experiments}


253 To investigate whether titi monkeys respond to human presence as they do when facing a potential

254 predator, an experiment was carried out where monkeys were exposed to a clothed mannequin

255 sitting on a chair (Fig. 3). On the day prior to an experimental session, one observer (LHL) followed

256 the experimental group until it settled for the night. Next morning, before dawn, the mannequin was

257 placed in an open area, where it was predicted that the group would emerge after leaving the

258 sleeping tree. The two observers waited for the titis to arrive while concealed in the vegetation, 5-10

259 m away from the mannequin. Upon the titis' arrival, one observer (LHL) reported at low voice the

260 ad libitum behavior of group members on a mobile phone while a second observer (PA) videotaped

261 the whole episode with a Canon XL-H1 camcorder equipped with a wide-angle lens and a

262 Seenheiser ME66-K6P microphone.

263 To prevent the monkeys from habituating to the mannequin, we performed only one

264 successful session per group. A “successful session” was an experimental session in which at least

265 one individual in the group saw the mannequin. If the group failed to appear, the experimental

266 session was reported as a "failed session". In this case, another experimental session was performed

267 on a subsequent day until we got a successful session. An experimental session ended when all

268 group members withdrew from the area. The six groups of titi monkeys were partly habituated to the

269 presence of one observer (LHL) when we began testing. It is unlikely that the titis responded to the

270 concealed observers as they seemed more distracted by the mannequin, which was quite visible on

271 the ground.

272 The video recordings were visualized with Adobe Premiere Pro CC (v. 2015). Despite

273 having used a wide-angle lens for filming the titis, not all group members were visible in the video

274 clips. For a detailed description of the titis' behavior during a successful trial, we mostly relied on

275 the in-situ observations (Article S1). Nevertheless, the video footage was useful to confirm which 
276 group member approached the mannequin and estimate the approach distance. The titis' vocal

277 response was highly variable between groups and, in contrast with the conspicuous mouth

278 movements associated with loud calling, the soft and high-pitched alarm calls are produced with the

279 mouth barely opened. Thus, in most trials, we were unable to rigorously identify the callers, both in

280 situ and from the video footage. We therefore exported the sound track as a WAV file and generated

281 spectrograms of the calls using Raven Pro (v. 1.5). For scoring, we followed Cäsar's classification

282 scheme of black-fronted titis, Callicebus nigrifrons, alarm calls, based on call shape (Cäsar et al.,

283 2012). We carefully inspected the spectrograms and counted all occurrences of each call type (A

284 'chirp', B ‘cheep', C ‘squeaks’, W ‘whistle’; Fig. S1) emitted "per group” during a given trial.

285 Except for the whistle, these faint, high-pitched alarm calls, less than $100 \mathrm{~ms}$ in duration, were

286 delivered in short series at a rate of 6 to 8 calls/s. All exhibited a putative fundamental sound (F0)

287 between 4 and $5 \mathrm{kHz}$ with at least one visible harmonic. To standardize the data, we retained those

288 emitted in the first minute following detection of the mannequin by the group (Cäsar et al., 2013).

289

\section{Fecal sampling and cortisol enzyme immunoassays (EIA)}

291 During behavioral observations, the observer paid particular attention to fecal deposition by resting

292 group members. When defecation occurred, the site where the droppings landed was immediately

293 searched and the fresh sample was collected with disposable gloves. Such diversion terminated a

294 session of observation and usually resulted in the loss of visual contact with the group. From each

295 sample, $0.1 \mathrm{~g}$ of stool was extracted, weighed with a portable precision scale (OHAUS model

296 YA302) and then placed in $15 \mathrm{ml}$ polypropylene tubes containing a mix of $2.5 \mathrm{ml}$ of distilled water

297 and $2.5 \mathrm{ml}$ of ethanol (Ziegler \& Wittwer, 2005). Each tube was tightly capped, sealed with parafilm

298 and carefully labeled with a date, sample number, individual identity and time of fecal deposition. 
299 We set out to collect as many fresh samples as possible from each individual but ended up with

300 fewer than we thought, which is a weakness of our study. The 30 fecal samples were collected

301 opportunistically throughout the day (Table 4), and came from 19 identified individuals (out of the

30226 monitored individuals). The samples were stored in a freezer until they were exported and

303 processed for cortisol analysis at the Paleogenomic and Molecular Genetics laboratory at the Musée

304 de l'Homme in Paris, France. Using the salivary cortisol assay kit from Salimetrics ${ }^{C}$, enzyme-

305 immunoassays were performed to assess the effectiveness of cortisol antibodies in binding to fecal

306 metabolites in Bolivian gray titi monkeys. We provide a technical report of parallelism and

307 validation tests of this glucocorticoid (Article S2). All applicable institutional, national and

308 international guidelines for the care and use of animals were followed. We obtained research

309 approvals and export permits from the National Biodiversity Authority in Bolivia (MMAYA-

310 VMABCCGDF-DGBAP/MEG N0531/2018) and from the National Service of Food Safety and

311 Agricultural Health (SENASAG 0040452), respectively, and import permit from the Direction

312 Départementale de la Protection des Populations de Paris (N²018-75-31555).

\section{Statistics}

315 To account for temporal pseudoreplication, sound pressure values were fitted to a generalized

316 mixed-effects model in which three categorical variables (orientation, extreme values, time of day)

317 and one covariate (distance to highway) were entered as fixed effects. Because measures obtained

318 from each transect were made on separate days, we included a random effect term for varying

319 intercepts by transects, and for recording stations that are nested within transects. To examine the

320 changes occurring in both acoustic indices as a function of distance to the highway, we performed 
321 Least Squares Regression analyses on the log transformed data. For normality assumptions, we

322 relied on the Shapiro-Wilks test.

323 To assess whether titis' behavior was affected by the disturbance (anthropophony and

324 anthropic activity), we applied the Chi-square test goodness of fit to compare within-group

325 frequencies of behavior and the number of individual occurrences in each forest level. The Pearson's

326 Chi-square was performed to compare the between-group activity budgets and forest level

327 utilization. We did not perform the test when the cells in the contingency tables contained an

328 expected frequency less than 1 or less than 5 in more than $20 \%$ of cases. Second, to analyze changes

329 in activity budgets as a function of distance to the highway, we performed analyses of covariance,

330 following Crawley's (2014) recommendations. Here, the response variable was a matched pair of

331 counts (occurrences in one behavioral category vs. other categories) that we wished to analyze as

332 proportion data. Therefore, we applied generalized linear models (GLM) fitted for binomial data in

333 which two categorical variables (sex, age) and one covariate (distance to highway) were entered as

334 fixed effects.

To assess whether titis responded differentially to the mannequin in each of the three areas of

336 varying anthropic disturbance, we used a $\mathrm{G}$ test for goodness of fit to determine if there was an

337 overall difference in the proportion of calls emitted per group and per area of human disturbance.

338 To account for the variation in the number of individual fecal samples within each group, we

339 performed a mixed-effects linear model in which we evaluated the effect of group distance (as

340 covariate) on cortisol concentration, with a random factor in which individuals were nested within

341 group. In addition, age was entered in the model as a categorical fixed factor by aggregating group

342 members into either 'adult' category, which included adult males, adult females and sub-adults $(\mathrm{n}=$

343 11) or 'young' category, which included juveniles and infants $(\mathrm{n}=8)$. To relate cortisol 
344 concentrations with each class of noise level, we used a Pearson correlation test. We first calculated

345 the mean RMS and M values obtained at each site in the course of 24 hours. These mean values

346 were then averaged across the four sampling sites of each home range, which gave us six overall

347 mean values for each acoustic index. Similarly, given little within-group variation (no sex or age

348 difference), cortisol concentrations were averaged, thus resulting in six mean cortisol values that

349 were representative of each group.

350 The models were fitted with restricted maximum likelihood, using the 'nlme' R package

351 (v.3.6.1) and we selected the one with the lowest Akaike information criterion (AIC). Pearson

352 residuals were visualized with the package 'corrplot' of $\mathrm{R}$ and post-hoc tests were performed with

353 Bonferroni corrections. All statistical models are reported in Table S1.

354

355 RESULTS

\section{Sound pressure gradient}

357 GLMM analysis using the log transformed data pointed to the model devoid of interactive factors as

358 the most parsimonious one, based on Akaike information criterion (Table S1.1). The additive model

359 detected significant contributions of each factor (Wald test: $\chi_{\text {orientation }}^{2}=5.75, \mathrm{df}=1, \mathrm{p}=0.016$;

$\left.360 \chi_{\text {extreme values }}^{2}=1698.13, \mathrm{df}=1, \mathrm{p}<0.001 ; \chi_{\text {time of day }}^{2}=90.59, \mathrm{df}=4, \mathrm{p}<0.001\right)$ and the covariate

361 (Wald test: $\chi^{2}$ distance $=41.52, \mathrm{df}=1, \mathrm{p}<0.001$ ) on sound pressure (Fig. 4A). Irrespective of the

362 sensor orientation (northward or southward), there was a non-linear decay process in sound pressure

363 from the highway towards Campo Verde (Fig. 4B). Moreover, minimum SPL fitted the regression

364 line better than maximum values $\left(\operatorname{var}_{\operatorname{minN}}=66.3 ; \operatorname{var}_{\operatorname{minS}}=61.0 ; \operatorname{var}_{\operatorname{maxN}}=152.9 ; \operatorname{var}_{\operatorname{maxS}}=140.0\right)$.

365 Overall, minimum SPL dropped sharply from the highway (mean \pm SD: $66.4 \pm 3.0 \mathrm{~dB}$ ) to a distance

366 of $100 \mathrm{~m}(52.5 \pm 4.5 \mathrm{~dB})$ with an additional decay of $8.3 \mathrm{~dB}$ up to $800 \mathrm{~m}(44.2 \pm 4.4 \mathrm{~dB})$. Linearity 
367 in the dataset was obtained after excluding SPL measurements at $1 \mathrm{~m}$ from the highway.

368 Subsequently, ANCOVA performed on the restricted dataset (100-800 m) revealed a significant

369 interaction between distance and time-of-day ( $\mathrm{h} 18 \mathrm{x}$ distance: $\mathrm{t}=-2.919, \mathrm{p}=0.004$; Table S1.2).

370 Specifically, we observed little change in the noise gradient during the course of the day, except at

371 18:00 h when sound pressure levels increased significantly due to the onset of the cicadas' dusk

372 chorus (Fig. 4).

373

\section{Characterization of noise}

375 Both RMS and M acoustic indices were inversely correlated with the distance to the highway, 376 exhibiting a steeper slope during the day, as compared with nocturnal values (Pearson correlation 377 test for RMS: $\mathrm{r}_{\text {day }}=0.78, p<0.001, \mathrm{r}_{\text {night }}=0.67, p<0.001$; Pearson correlation test for M: $\mathrm{r}_{\text {day }}=$ $3780.80, p<0.001, r_{\text {night }}=0.78, p<0.001$; Figs. 2B and 2D). Inside each group's home range, except 379 for RMS values in G4 (Fig. 2C) and M values in G6 (Fig. 2E), both indices were significantly 380 higher during the day than during the night (paired t-tests: $\mathrm{t} \geq 3.13$, $\mathrm{df}=71, \mathrm{p}<0.01 ; \mathrm{t} \geq 4.52$, $\mathrm{df}=$ $38171, \mathrm{p}<0.001$, respectively). Furthermore, both indices exhibited a strong circadian pattern in the 382 reference area (G0), with a gradual attenuation at increasing distances from the highway (Figs. 2F 383 and $2 \mathbf{G})$.

385 Time budgets, social relationships and use of space by the titis

386 First, we examined whether home range size differed among family groups. The reconstruction in 387 Google Earth of 75 tracks (mean length \pm SD: $255.0 \pm 178.9$ m) obtained from 282 hours of 388 behavioral observations revealed small, overlapping home ranges (range: $1.35-3.38$ ha) with groups 389 G1 and G2 exploiting a relatively larger area (Figs. 2A, 5A). We found no difference in the groups' 
390 travel speed after log-transformation of the data (mean \pm SD: $81.6 \pm 11.3 \mathrm{~m} / \mathrm{h}$, ANOVA: $\mathrm{F}_{5,69}=$

$3910.84, p=0.52$; Table 2). Daily paths obtained from three complete days in three groups averaged

$392569.3 \pm 36.9 \mathrm{~m}$.

393 Second, we examined whether activity budgets and use of forest strata differed among family

394 groups. Within each group, the titis spent most of their time resting (mean \pm SD: $38.6 \pm 6.3 \%$ ) and

395 allocated less time to moving $(22.8 \pm 2.7 \%)$, foraging $(21.1 \pm 4.3 \%)$, observing $(11.6 \pm 3.7 \%)$ and

396 socializing $(5.9 \pm 2.3 \%$; Figs. 5B and 5D). When socializing, the main behaviors were vocalizing

$397(47.3 \pm 20.2 \%, \mathrm{n}=70)$, grooming $(22.6 \pm 14.8 \%, \mathrm{n}=40)$ and tail twining $(15.2 \pm 14.3 \%, \mathrm{n}=30)$

398 whereas both play and agonistic behaviors occurred sporadically $(8.3 \pm 6.3 \%, \mathrm{n}=15$ and $6.6 \pm$

$3995.3 \%, \mathrm{n}=9$, respectively). Interestingly, family groups spent significantly more time in the lower

400 forest stratum than higher up (S1: $68.74 \pm 7.92 \%, \mathrm{~S} 2: 28.82 \pm 7.49 \%$, S3: $2.43 \pm 1.94 \%$; Wilcoxon

401 signed-rank test comparing $\mathrm{S} 1$ vs. $\mathrm{S} 2+3: \mathrm{V}=0, \mathrm{p}=0.031$; Figs. 5C and 5E). Moreover, their

402 activity budgets differed accordingly (Table 5): moving occurred more frequently than expected in

403 the lower stratum (S1: $26.01 \pm 1.98 \%$ vs. S2+S3: $13.82 \pm 3.97 \%$; Wilcoxon signed-rank test: V=0,

$404 \mathrm{p}=0.031)$ whereas foraging tended to be more frequent than expected in the higher strata (S1: 18.07

$405 \pm 4.87 \%$ vs. S2+S3: $29.50 \pm 7.84 \%$; Wilcoxon signed-rank test: $\mathrm{V}=1, \mathrm{p}=0.063)$. Analysis of

406 standard residuals revealed significant between-group differences both in activity budgets (Pearson's

407 Chi-square: $\left.\chi^{2}=107.4, \mathrm{df}=20, \mathrm{p}<0.001\right)$ and use of forest strata $\left(\chi^{2}=64.5, \mathrm{df}=5, \mathrm{p}<0.001\right)$.

408 ANCOVA analysis per age class (adult vs. young) disclosed subtle but significant changes in

409 specific activities according to home range distance to the highway (Table S1.3). In particular,

410 regression analysis with binomial errors showed that the time spent moving by adult pairs increased

411 significantly with home range distance to the highway (male-female: $\mathrm{z}_{\text {distance }}=3.06, \mathrm{p}=0.002 ; \mathrm{z}_{\mathrm{sex}}=$

$4120.74, \mathrm{p}=0.461 ;$ Fig. $\mathbf{5 F})$ and this tended to be significant for each sex taken separately $\left(\mathrm{z}_{\mathrm{female}}=\right.$ 
$\left.4132.53, p=0.011 ; z_{\text {male }}=-1.85, p=0.065\right)$. No such relationship was found in the activity budget of

414 young animals (infant-juvenile: $\mathrm{z}_{\mathrm{distance}}=0.30, \mathrm{p}=0.77 ; \mathrm{z}_{\mathrm{age}}=-1.67, \mathrm{p}=0.08$; Fig. 5G). Thus, adult

415 pair locomotion was inversely related to the gradient observed in both acoustic indices (RMS and $416 \mathrm{M})$.

Lastly, we examined whether social relationships differed among family groups. From a total of 2439 measures of social proximity, tight social dyads $(63.9 \%)$ were more frequent than loose social dyads (13.7\%). Likewise, tight groupings $(18.5 \%)$ occurred more frequently than loose groupings $(0.5 \%)$ and the focal animal was rarely found solo $(3.5 \%)$. Tight social dyads (n $421=1558)$ consisted predominantly of the adult pair (FM: $31.0 \pm 10.3 \%)$, less frequently of one adult

422 next to a juvenile (FJ: $14.8 \pm 6.5 \%, \mathrm{MJ}: 10.5 \pm 6.3 \%$ ) or next to an infant (FI: $13.9 \pm 6.7 \%$, MI: $42313.5 \pm 4.4 \%)$. Still fewer records entailed a juvenile next to an infant $(8.6 \pm 6.0 \%)$ whereas social 424 dyads involving a sub-adult were least observed (SF: $9.0 \pm 0.1 \%$, SM: $4.1 \pm 5.8 \%$, SJ: $4.6 \pm 1.4 \%$, 425 SI: $5.1 \pm 4.0 \%$ ). Overall, we found no evidence of a gradual change in social relationships as a 426 function of group location relative to the highway.

427

\section{Response to the mannequin}

429 In total we performed 18 experimental sessions, 12 of which were unsuccessful (66.7\%). For each 430 successful session $(n=6)$, group members approached the visual model within a radius of $4 \mathrm{~m}$ with 431 a mean latency of $86.7 \pm 16.9$ minutes (Table 6). As we expected, the two groups most exposed to 432 human disturbance showed either no obvious reaction to the mannequin $(\mathrm{G} 1)$ or reacted weakly with 433 piloerection and brief calling $(\mathrm{G} 2)$. By contrast, groups residing in quieter areas reacted either 434 strongly (G3: 150 calls during the first minute) or moderately (G4: 62 calls, G5: 59 calls, G6: 71 435 calls $)\left(G\right.$ test: $\left.\mathrm{G}_{\text {group }}=325.87 ; \mathrm{df}=5, \mathrm{p}<0.001 ; \mathrm{G}_{\text {area }}=286.4 ; \mathrm{df}=2, \mathrm{p}<0.001\right)$. While looking at 
436 the mannequin, the titis from these groups exhibited typical postures with signs of arousal, such as

437 arching the back with piloerection (Article S1). From a total of 343 vocal emissions, three types of

438 calls were identified (Table 6): the most common type was call B (97.4\%), then call C (2.3\%), lastly

439 the whistle $(0.3 \%)$. However, against our prediction, the titis' alarm response to the mannequin did

440 not squarely correlate with group location relative to the highway as groups G5 and G6 responded

441 less to the mannequin than did groups G3 and G4 (post-hoc tests: $\chi_{\text {area1 }}^{2}=-12.98, \mathrm{p}<0.001, \chi_{\text {area2 }}^{2}=$

$\left.44211.19, \mathrm{p}<0.001, \chi_{\text {area3 }}^{2}=1.79, \mathrm{NS}\right)$.

443

\section{Fecal cortisol concentrations}

445 Enzyme immunoassays of 30 fecal samples issued from 19 individuals detected low cortisol

446 concentrations (mean $\pm \mathrm{SD}: 0.14 \pm 0.06 \mu \mathrm{g} / \mathrm{dL}$, range: $0.05-0.34 \mu \mathrm{g} / \mathrm{dL}$ ) with little between-group

447 variation (Table 4). Two samples were three standard deviations above average but the normality 448 assumption was met after log-transformation of the data (Shapiro-Wilks test: $\mathrm{W}=0.95 ; p=0.16$ ). A

449 linear mixed effects analysis with age and distance as fixed factors and individuals nested within 450 group as a random factor revealed no significant difference between the full and reduced models 451 (Table S1.4). The retained model detected no significant effect of the fixed factors (Wald test: $\chi^{2}$ age $452=0.84, \mathrm{df}=1, \mathrm{p}=0.36 ; \chi^{2}$ distance $\left.=0.25, \mathrm{df}=1, \mathrm{p}=0.62\right)$. The random effect accounted for $48.4 \%$ of 453 the variance left over after the variance explained by the fixed effects (Fig. 6A). The timing of 454 sample collection had no effect on cortisol concentration (morning: $0.14 \pm 0.07 \mu \mathrm{g} / \mathrm{dL}, \mathrm{n}=15$; 455 afternoon: $0.12 \pm 0.07 \mu \mathrm{g} / \mathrm{dL}, \mathrm{n}=11$; Wilcoxon rank sum test: $\mathrm{W}=53, \mathrm{p}=0.13)$. Pearson 456 regression analysis found both acoustic indices highly correlated $\left(\mathrm{M}-\mathrm{RMS}: \mathrm{F}_{1,4}=56.91 ; \mathrm{p}=0.002\right)$. 457 Against our prediction, however, we found no relationship between hormonal concentrations and the 
$458 \log$ of the noise gradient in the study area $\left(\mathrm{M}-\mathrm{CORT}: \mathrm{F}_{1,4}=0.26 ; \mathrm{p}=0.635 ; \mathrm{RMS}-\mathrm{CORT}: \mathrm{F}_{1,4}=\right.$ 459 0.12; $p=0.744$; Fig. 6B).

460

\section{DISCUSSION}

462 In line with our hypothesis, the anthropogenic noise seemed to impact the titis' behavior in two 463 ways. First, as a between-group variation in the activity budgets of adult pairs: the more exposed 464 they were to anthropophony, the less time they spent moving. Second, our field experiment using a 465 mannequin indicated a reduction in the titis' alarm response as a result of habituation to human 466 presence. Against our prediction, however, we found no evidence of stress-related elevation of fecal 467 cortisol, as would be expected in animals exposed to chronic anthropogenic perturbation (Cross et 468 al., 2004; Kaplan et al., 2012).

\section{Highlighting the anthropogenic noise gradient in the titis' habitat}

471 We confirmed the presence of a noise gradient in the study area. First, sound pressure measurements 472 with the sound level meter oriented northward and then southward clearly point to noise attenuation

473 from the highway up to the suburb of Campo Verde, and not the reverse. This shows that roadway

474 traffic, not the suburb, was the main source of the noise gradient. Of interest, maximal sound 475 pressure values exhibited more variability than did minimal sound pressure values. The noise 476 gradient persisted throughout the day with little fluctuation, except in the evening hours with the 477 onset of the cicadas' chorus. Indeed, cicadas may produce some of the loudest sounds among living 478 organisms, as has been reported for Cistosoma saundersii with sound pressure peaking at $158 \mathrm{~dB}$ 479 inside the air sac (Young \& Bennet-Clark, 1995). Because of its persistence, the cicadas' dusk 
480 chorus affected both maximum and minimum SPL readings. Although less intense than stridulating

481 cicadas, roadway traffic noise was perceptible from dawn to dusk, and into the night.

482

The native forest in the park might have acted as a noise barrier, especially for high-

483 frequency sounds, but we found no clear pattern of excess attenuation. From 100m off the highway

484 up to the quiet suburb of Campo Verde, sound pressure decayed linearly and smoothly, with an

$4858.3 \mathrm{~dB}$ drop in background noise. Under free field conditions, a $6 \mathrm{~dB}$ drop is expected with a doubling

486 of the distance from the sound source (inverse square law). Absence of excess attenuation can be

487 attributed to the presence of multiple, heterogeneous sound sources, both spatially and temporally

488 distributed in the study area. Although well-controlled sound transmission experiments might have

489 confirmed a barrier effect of the native forest, this topic was outside the scope of our study.

490 Second, using passive acoustic monitoring, we confirmed the presence of a noise gradient,

491 as evidenced by the RMS and M acoustic indices (Depraetere et al., 2012; Rodriguez et al., 2013;

492 Eldridge et al., 2018). We were unable to dissociate the relative contribution of roadway traffic and

493 human activity from the audio recordings. However, we note that the noise gradient persisted at

494 night when human presence inside the park was highly reduced. Furthermore, compared with the

495 nocturnal values of the acoustic indices, the diurnal values were generally higher and the noise

496 gradient exhibited a steeper slope, supporting the view of increased diurnal anthropophony, roadway

497 traffic and human activity combined (for similar circadian patterns in soundscape dynamics, see

498 Duarte et al., 2015). Obviously, multiple recorders deployed in the titis' home ranges would have

499 provided a more robust methodology to assess the moment-to-moment changes in soundscape across

500 the entire area. Nevertheless, our rotation schedule with a single recording platform shows that

501 relevant patterns of soundscape can be revealed over time with minimal equipment (see also Turner,

502 Fischer \& Tzanopoulos, 2018). 
An important issue, of course, is whether titi monkeys are sensitive to traffic noise.

504 Behavioral audiograms for callicebine monkeys are lacking but we note that the auditory sensitivity

505 of the closely related owl monkey, Aotus trivirgatus, is similar with that of humans at $500 \mathrm{~Hz}$

506 (Nummela, 2017). In general, Neotropical monkeys are most sensitive to sound above $2 \mathrm{kHz}$

507 (reviewed in Heffner, 2004; Nummela, 2017), suggesting that roadway traffic may be less disturbing

508 for them. However, traffic noise covers a broad frequency spectrum and sound energy remains

509 substantial up to $10 \mathrm{kHz}$. Small-headed Neotropical monkeys exhibit their best frequency at $\sim 8 \mathrm{kHz}$

510 (Aotus, Callithrix) and $\sim 12 \mathrm{kHz}$ (Saimiri), which is much higher than the human best frequency (4

$511 \mathrm{kHz}$ ) at a similar threshold of loudness (Heffner, 2004). For these monkeys, traffic noise in the high

512 frequency range might represent a source of disturbance. At this point, we can only speculate until

513 studies on the hearing abilities of titi monkeys become available.

514

\section{Behavioral changes associated with a gradient of noise levels}

516 Interestingly, the titis' activity budgets seemed to be affected by the anthropogenic noise gradient, as

517 indicated by a negative interaction between the noise levels and adult pair locomotion. The

518 behavioral change occurred within a gradient of minimum sound pressures ranging approximately

519 from $44 \mathrm{~dB}(\mathrm{~A})$ to $52 \mathrm{~dB}(\mathrm{~A})$. These noise levels stand above the coterminous USA range for natural

520 sounds devoid of human influence (24-40 dB LAeq; Shannon et al., 2016) and approximate those

521 reported at sites close to and far from an open-cast mine in Brazil (Duarte et al., 2015). In fact, the

522 mining noise was loud enough to impact the calling patterns of black-fronted titi monkeys (Duarte et

523 al., 2017). Correlative changes in songbird vocal activity have also been observed along a noise

524 gradient within an urban park (Díaz et al., 2011). Whether this noise-related change in the titis'

525 locomotion results from anthropogenic disturbance or is fortuitous (i.e. correlation without 
526 causation) remains to be explored. Although little is known about the consequences of sleep deficits

527 in free-ranging nonhuman primates (Reinhardt et al., 2019), one possibility is that nocturnal traffic

528 noise might disrupt sleep patterns, more so in adults than their putative offspring. Adult pairs

529 experiencing sleep disruption near the highway would then compensate with longer or more

530 frequent naps during the day. In female frogs, traffic noise significantly increases tonic immobility

531 response with concomitant elevation of plasma corticosterone concentrations (Tennessee, Parks \&

532 Langkilde, 2014).

533 The titis' alarm response to a mannequin was weaker in groups most exposed to anthropic

534 disturbance $(\mathrm{G} 1, \mathrm{G} 2)$, thus revealing a potential habituation to human presence. However, contrary

535 to our hypothesis, their response did not vary according to the degree of human disturbance in each

536 of the three areas of the park. Of the six study groups, the one that resided in the area with moderate

537 human disturbance (G3 in area 2, where human intrusion was less likely due to dense bamboo

538 vegetation) exhibited the strongest response to the mannequin. This group carried an un-weaned

539 infant, which could explain their strong reaction to the mannequin. In all successful trials, call B was

540 the predominant call type emitted by the titis during the first minute after detecting the mannequin.

541 Previous studies of black-fronted titis' alarm calls (Cäsar et al., 2012, 2013) reported that call B is

542 given in a variety of situations, the context of which is specified by the position of the call in the

543 overall sequence. For instance, the appearance of a terrestrial predator or any kind of disturbance on

544 the ground will trigger call $\mathrm{B}$, which is also emitted while the titis are descending or foraging close

545 to the ground. Of interest, non-habituated groups of black-fronted titis also produced call B in

546 response to human presence (Cäsar et al., 2012). Although our subjects might have viewed the

547 mannequin as a human, performing control tests with a scrambled, desarticulated mannequin could

548 have shed light on this issue. 


\section{Relationship between the noise gradient and fecal cortisol}

551 Contrary to our expectation, fecal cortisol levels measured in the six study groups were unrelated to

552 the noise gradient. It is conceivable that the absence of increased fecal cortisol in groups residing

553 near the highway was due to the rather low statistical power of our data and the variable time in

554 sample collection, thus limiting the scope of our study. Although time of day had no effect on

555 cortisol titers, a more adequate sampling might have shown the presence of a diurnal cycle in

556 cortisol secretion. Such pattern has been reported for the squirrel monkey and common marmoset,

557 revealing a diurnal decrease, both in circulating and salivary cortisol (Coe \& Levy, 1995; Cross \&

558 Rogers, 2004). For fecal cortisol, however, higher levels were measured in the afternoon, not in the

559 morning, thus reflecting the time necessary for hormonal excretion (Souza \& Ziegler, 1998; but see

560 Feirrera Ravinelli et al., 2001). In primates, the lag time for the appearance of fecal cortisol is

561 affected by body size, diet and gut transit time, with the response occurring within 4-48 hours of a

562 stressful event (Rangel-Negrin et al., 2009; Wark et al., 2016; Chen et al., 2017). Environmental

563 stressors other than noise could also have confounded cortisol titers in our subjects. For instance, we

564 did not take into account group size, inter-group social conflicts, food resources and predation risk,

565 all of which are potential sources of chronic stress that could potentially override subtler variations

566 induced by the noise gradient. Further work involving a larger sample of feces will be needed to

567 clarify these points.

568 Fecal glucocorticoids are expected to be less concentrated than circulating hormones, but

569 the levels we measured in $P$. donacophilus are $\sim 200$ times lower than plasma cortisol reported for $P$.

570 cupreus in captivity (Hennessy et al., 1995; Ragen et al., 2013; Fisher-Phelps et al., 2015; Hostetler

571 et al., 2016) and about $\sim 100$ times lower than fecal cortisol measured in other Neotropical monkeys 
572 (Albuquerque et al., 2001; Ange-van Heugten et al., 2009; Wheeler et al., 2013; Cantarelli et al.,

573 2017; Price et al., 2019). Our fresh fecal samples were immersed in aqueous alcohol solution and

574 then transferred to a freezer. Storage in alcohol prevents degradation of hormonal metabolites by

575 bacterial metabolism, even at room temperature (Hodges \& Heistermann, 2011; Kalbitzer \&

576 Heistermann, 2013). Nevertheless, we cannot exclude the possibility that the dilution might have

577 caused the loss of signal, prior to analysis. Lastly, our choice of using an EIA kit normally used for

578 salivary cortisol might explain its weak reactivity to fecal extracts, thus resulting in low hormone

579 concentrations in all individuals, regardless of age, sex, time-of-day and home range location

580 relative to the highway. However, none of the most relevant problems associated with EIA (Brown,

581 Walker \& Steinman, 2005) was identified in our assay protocol. In fact, the presence of two higher

582 cortisol values obtained from one adult female shows that the Salimetrics kit was working.

583

Admittedly, along with our chemical validation, it would have been useful to perform a

584 physiological validation with some type of acute stress or with a pituitary trophic hormone (ACTH)

585 stimulant to induce maximal glucocorticoid release and thus determine the biological range of

586 cortisol concentration in our population (Brown et al., 2004; Wheeler et al., 2013; Behringer \&

587 Deschner, 2017). Such a test, however, required the capture and restraint of an animal, which was

588 not possible during the study period. Finally, three groups of titis had weaned infants but it is very

589 unlikely that the females in those groups - including the one that provided the highest cortisol titers

590 - were pregnant at the time of sample collection. In female tamarins, fecal cortisol has been shown

591 to rise in late pregnancy (Bales et al., 2005; Price et al., 2019).

592

593 Relevance to primate conservation 
595 monkeys. Consistent with a previous study (Dingess, 2013), the titis’ home ranges at Yvaga Guazú

596 overlap substantially and their size is among the smallest reported for the subfamily Callicebinae

597 (Norconk, 2007; Bicca-Marques \& Heymann, 2013; Huck, Di Fiore \& Fernandez-Duque, 2020).

598 Furthermore, the titis' travel speed $(78-95 \mathrm{~m} / \mathrm{h})$ in the park was quite low compared with that (300-

$599420 \mathrm{~m} / \mathrm{h}$ ) reported for the masked titi monkey, Callicebus nigrifrons, in a much larger patch of

600 Atlantic forest (Nagy-Reis \& Setz, 2017). This is not surprising given the heavy deforestation

601 around the park with little opportunity for family group dispersion. The titis, however, spent most of

602 their time resting, which accords with activity budgets of other callicebine monkeys (Caselli \& Setz,

603 2011; Bicca-Marques \& Heymann, 2013; Kulp \& Heymann, 2015; van der Speld, Bello \& Hebard,

604 2017; Dolotovskaya \& Heymann, 2020). These cryptic and shy animals have been reported to thrive

605 in disturbed and/or fragmented forests (Bicca-Marques \& Heymann, 2013), despite the negative

606 effects of road networks on animal and plant communities (Gill, Sutherland \& Watkinson, 1996;

607 Laurance, Goosem \& Laurance, 2009; Hernani-Lineros, Garcia \& Pacheco, 2020). Evaluating

608 further their tolerance threshold to anthropogenic noise will assist in the conservation and

609 management of their populations (Rumiz, 2013; Shanee et al., 2013; Wallace et al., 2013). Finally,

610 three of our study groups had un-weaned infants suggesting that population growth at Yvaga Guazú

611 was not constrained by the level of human disturbance, an indication that this peri-urban population

612 of titis is able to cope with human disturbance.

613

\section{CONCLUSION}

615 Emerging from this study are changes in the titis' behavior in association with increased human

616 disturbance. Concomitantly, our physiological data using fecal cortisol as a proxy for chronic stress 
617 are suggestive of the titis' resilience to anthropic perturbation, but do not allow us to draw firm

618 conclusions owing to sampling issues. Though this topic merits further investigation, a major

619 emphasis of this study has been to combine a suite of acoustical, behavioral and hormonal

620 methodologies, supplemented by field experiments. Such conceptual framework is worth pursuing if

621 we are to disentangle the complex interactions between human disturbance, behavior and stress

622 physiology in naturalistic settings. In addition, laboratory studies are needed to elucidate the

623 auditory sensitivity of titi monkeys to anthropic noise and to assess hormonal responses under more

624 controlled conditions, via playback experiments. We hope that the present study will stimulate

625 further research in those directions.

626

627 ACKNOWLEDGMENTS

628 Part of the work reported here was executed by LHL to fulfill a Master's degree at the Universidad

629 Mayor Sans Andrés, La Paz (Bolivia). The Museo de Historia Natural Noel Kempff Mercado

630 provided institutional support through Kathia Rivero, Head of Vertebrate Zoology, to obtain

631 research approvals and export permits from the National Biodiversity Authority. Engineer César

632 Perez Alcover developed the timer for passive acoustic monitoring. For the processing of biological

633 samples, we thank the Plateau de Paléogénomique et Génétique Moléculaire (P2GM), Museum

634 National d'Histoire Naturelle, Paris, France. We are most indebted to Emeritus Professor Michel

635 Kreutzer for insightful comments on an early draft of the manuscript. Special thanks are due to

636 Rebeca Rozenman Attie and Francisco Hübsch, landowners of the Ecological Park of Yvaga Guazú.

637 We also thank Rosely Ligeron Arteaga and Franco Oscar Echenique Robles for field assistance at an 638 early stage of the study.

639 


\section{REFERENCES}

641 Adams CE. 2016. Urban wildlife management. $3^{\text {rd }}$ Ed., Taylor \& Francis Group, New York: CRC

642 Press.

643 Albuquerque ACSR, Sousa MBC, Santos HM, Ziegler TE. 2001. Behavioral and hormonal analysis

644 of social relationships between oldest females in a wild monogamous group of common marmosets

645 (Callithrix jacchus). International Journal of Primatology 22: 631-645. DOI:

646 10.1023/A:1010741702831

647 Altmann J. 1974. Observational study of behaviour: sampling methods. Behaviour 49: 227-266.

648 DOI: $10.1163 / 156853974 \times 00534$

649 Ange-van Heugten KD, van Heugten E, Timmer S, Bosch G, Elias A, Whisnant S, Swarts HJM, 650 Ferket P, Verstegen MWA. 2009. Fecal and salivary cortisol concentrations in woolly (Lagothrix 651 ssp.) and spider monkeys (Ateles spp.). International Journal of Zoology 2009: Article ID 127852.

652 DOI: $10.1155 / 2009 / 127852$

653 Bales K. French JA, Hostetler CM, Dietz JM. 2005. Social and reproductive factors affecting 654 cortisol levels in wild female Golden lion tamarins (Leontopithecus rosalia). American Journal of 655 Primatology 67: 25-35. DOI: 10.1002/ajp.20167

656 Barber JR, Crooks KR, Fristrup KM. 2010. The costs of chronic noise exposure for terrestrial 657 organisms. Trends in Ecology \& Evolution 25: 180-189. DOI: 10.1016/j.tree.2009.08.002

658 Bee M, Swanson EM. 2007. Auditory masking of anurans advertisement calls by road traffic noise. 659 Animal Behaviour 74: 1765-1776. DOI: 10.1016/j.anbehav.2007.03.019

660 Behie AM, Pavelka MSM, Chapman CA. 2010. Sources of variation in fecal cortisol levels in 661 howler monkeys in Belize. American Journal of Primatology 72: 600-606. DOI: 10.1002/ajp.20813 
662 Behringer V, Deschner T. 2017. Non-invasive monitoring of physiological markers in primates.

663 Hormones and Behavior 91: 3-18. DOI: 10.1016/j.yhbeh.2017.02.001

664 Bicca-Marques JC, Heymann EW. 2013. Ecology and behavior of titi monkeys (Callicebus). In:

665 Veiga LM, Barnett AA, Ferrari SF, Norconk MA, eds. Evolutionary biology and conservation of

666 Titis, Sakis and Uacaris. Cambridge University Press, 196-207. DOI:

$66710.1017 / \mathrm{CBO} 9781139034210.023$

668 Blickley JL, Patricelli GL. 2010. Impacts of anthropogenic noise on wildlife: research priorities for 669 the development of standards and mitigation. Journal of International Wildlife Law \& Policy 13:

670 274-292. DOI: 10.1080/13880292.2010.524564

671 Brown J, Gillooly J, Allen A, Savage V, West G. 2004. Toward a metabolic theory of ecology.

672 Ecology 85: 1771-1789. DOI: 10.1890/03-9000

673 Brown J, Walker S, Steinman K. 2005. Endocrine manual for reproductive assessment of domestic 674 and non-domestic species. Smithsonian's National Zoological Park, Conservation and Research 675 Center, Virginia, 1-69.

676 Brumm H, Slabbekoorn H. 2005. Acoustic communication in noise. Advances in the Study of 677 Behavior 35: 151-209. DOI: 10.1016/S0065-3454(05)35004-2

678 Brumm H. 2013. Animal communication and noise. Berlin (Germany): Springer. DOI: 10.1007/978$679 \quad 3-642-41494-7$

680 Cantarelli VI, Perez-Rueda MA, Kowalewski MM, Mastromonaco GF, Ponzio MF. 2017.

681 Validation of an enzyme immunoassay and comparison of fecal cortisol metabolite levels in black 682 and gold howler monkeys (Alouatta caraya) inhabiting fragmented and continuous areas of the 683 humid Chaco region, Argentina. American Journal of Primatology 79: 1-9. DOI: 10.1002/ajp.22625 
684 Cäsar C, Byrne RW, Young RJ, Zuberbühler K. 2012. The alarm call system of wild black-fronted

685 titi monkeys, Callicebus nigrifrons. Behavioral Ecology and Sociobiology 66: 653-667. DOI:

$68610.1007 / \mathrm{s} 00265-011-1313-0$

687 Cäsar C, Zuberbühler K, Young RJ, Byrne RW. 2013. Titi monkey call sequences vary with 688 predator location and type. Biology Letters 9(5): 20130535. DOI: 10.1098/rsbl.2013.0535

689 Caselli CB, Setz EZF. 2011. Feeding ecology and activity pattern of black-fronted titi monkeys 690 (Callicebus nigrifrons) in a semideciduous tropical forest of southern Brazil. Primates 52: 351-359.

691 DOI: $10.1007 / \mathrm{s} 10329-011-0266-2$

692 Chen H, Yao H, Yang W, Fan P, Xiang Z. 2017. Assessing the utility of urinary and fecal cortisol as 693 an indicator of stress in golden-nosed monkeys (Rhinopithecus roxellana). PeerJ 5/e3648 DOI:

$694 \quad 10.7717 /$ peerj.3648

695 Ciuti S, Northrup JM, Muhly TB, Simi S, Musiani M, Pitt JA, Boyce MS. 2012. Effects of humans 696 on behaviour of wildlife exceed those of natural predators in a landscape of fear. PLOS ONE 7:

697 e50611. DOI: 10.1371/journal.pone.0050611

698 Coe CL, Levine S. 1995. Diurnal and annual variation of adrenocortical activity in the squirrel 699 monkey. American Journal of Primatology 35: 283-292. DOI: 10.1002/ajp.1350350404

700 Crawley MJ. 2014. Statistics: An introduction using R. $2^{\text {nd }}$ Ed., Chichester: Wiley-Blackwell. DOI:

$701 \quad 10.18637 /$ jss.v067.b05

702 Cross N, Rogers LJ. 2004. Diurnal cycle in salivary cortisol levels in common marmosets.

703 Developmental Psychobiology 45: 134-139. DOI: 10.1002/dev.20023

704 Cross N, Pines MK, Rogers LJ. 2004. Saliva sampling to assess cortisol levels in unrestrained 705 common marmosets and the effect of behavioral stress. American Journal of Primatology 62: 107706 114. DOI: 10.1002/ajp.20005 
707 de Luna AG, Sanmiguel R, Di Fiore A, Fernandez-Duque E. 2010. Predation and predation attempts

708 on red titi monkeys (Callicebus discolor) and equatorial sakis (Pithecia aequatorialis) in Amazonian

709 Ecuador. Folia Primatologica 81:86-95. DOI: 10.1159/000314948

710 Depraetere M, Pavoine S, Jiguet F, Gasc A, Duvail S, Sueur J. 2012. Monitoring animal diversity

711 using acoustic indices: implementation in a temperate woodland. Ecological Indicators 13: 46-54.

712 DOI: $10.1016 / j . e c o l i n d .2011 .05 .006$

713 Díaz M, Parra A, Gallardo C. 2011. Serins respond to anthropogenic noise by increasing vocal

714 activity. Behavioral Ecology 22: 332-336. DOI: 10.1093/BEHECO/ARQ210

715 Dingess KA. 2013. Social flexibility in the classically monogamous titi monkey: a response to

716 increased population pressure. [Abstract] The 82 ${ }^{\text {nd }}$ Annual Meeting of the American Association of

717 Physical Anthropologists, 82:113.

718 Dolotovskaya S, Heymann EW. 2020. Do less or eat more: strategies to cope with costs of parental

719 care in a pair-living monkey. Animal Behaviour 163: 163e173. DOI: 10.1016/j.anbehav.2020.03.012

720 Duarte MHL, Vecci M, Hirsch A, Young RJ. 2011. Noisy human neighbours affect where urban

721 monkeys live. Biology Letters 7: 840-842. DOI: 10.1098/rsbl.2011.0529

722 Duarte M, Sousa-Lima RS, Young RJ, Farina A, Vasconcelos M, Rodrigues M, Pieretti N. 2015.

723 The impact of noise from open-cast mining on Atlantic forest biophony. Biological Conservation

724 191: 623-631. DOI: 10.1016/j.biocon.2015.08.006

725 Duarte M, Kaizer M, Young R, Rodrigues M, Sousa-Lima R. 2017. Mining noise affects loud call

726 structures and emission patterns of wild black-fronted titi monkeys. Primates 59: 89-97. DOI:

$727 \quad 10.1007 / \mathrm{s} 10329-017-0629-4$ 
728 Eldridge A., Guyot P, Moscoso P, Johnston A, Eyre-Walker Y, Peck M. 2018. Sounding out

729 ecoacoustic metrics: Avian species richness is predicted by acoustic indices in temperate but not

730 tropical habitats. Ecological Indicators 95: 939-952. DOI: 10.1016/j.ecolind.2018.06.012

731 Estrada A, Garber PA, Rylands AB, Roos C, Fernandez-Duque E, Di Fiore A, Nekaris KA, Nijman

732 V, Heymann EW, Lambert JE, Rovero F, Barelli C, Setchell JM, Gillespie TR, Mittermeier RA,

733 Arregoitia LV, de Guinea M, Gouveia S, Dobrovolski R, Shanee S, Shanee N, Boyle SA, Fuentes

734 A, MacKinnon KC, Amato KR, Meyer ALS, Wich S, Sussman RW, Pan R, Kone I, Li B. 2017.

735 Impending extinction crisis of the world's primates: Why primates matter? Science Advances 3:

736 e1600946. DOI : 10.1126/sciadv.1600946

737 Ferreira Raminelli JL, Cordeiro de Souza MB, Souza Cunha M, Veloso Barbosa MF. 2001. Morning

738 and afternoon patterns of fecal cortisol excretion among reproductive and non-reproductive male

739 and female common marmosets, Callitrhrix jacchus. Biological Rhythm Research 2: 159-167. DOI:

$740 \quad 10.1076 /$ brhm.32.2.159.1357

741 Fisher-Phelps ML, Mendoza SP, Serna S, Griffin L, Schaefer TJ, Jarcho MR, Ragen B, Goetze LR,

742 Bales KL. 2015. Laboratory simulations of mate-guarding as a component of the pair-bond in male

743 titi monkeys, Callicebus cupreus. American Journal of Primatology 78: 573-582. DOI:

$744 \quad 10.1002 /$ ajp. 22483

745 Frid A, Dill L. 2002. Human-caused disturbance stimuli as a form of predation risk. Conservation

746 Ecology 6: 11. DOI: 10.5751/ES-00404-060111

747 Gaynor KM, Hojnowski CE, Carter NH, Brashares JS. 2018. The influence of human disturbance on

748 wildlife nocturnality. Science 360: 1232-1235. DOI: 10.1126/science.aar7121 
749 Gill JA, Sutherland WJ, Watkinson AR. 1996. A method to quantify the effects of human

750 disturbance on animal populations. Journal of Applied Ecology, 33: 786-792. DOI:

$751 \quad 10.2307 / 2404948$

752 Giraudeau M, Nolan PM, Black CE, Earl SR, Hasegawa M, McGraw KJ. 2014. Song characteristics 753 track bill morphology along a gradient of urbanization in house finches (Haemorhous mexicanus).

754 Frontiers in Zoology 11:83. DOI: 10.1186/s12983-014-0083-8

755 Grace MK, Noss RF. 2018. Evidence for selective avoidance of traffic noise by anuran amphibians. 756 Animal Conservation 21: 343-351. DOI:10.1111/acv.12400

757 Heffner RS. 2004. Primate hearing from a mammalian perspective. The Anatomical Record Part A, 758 281A:1111-1122. DOI: 10.1002/ar.a.20117

759 Hendry AP, Gotanda KM, Svensson EI. 2017. Human influences on evolution, and the ecological 760 and societal consequences. Philosophical Transactions of the Royal Society London B Biological

761 Sciences 372(1712): 20160028. DOI: 10.1098/rstb.2016.0028

762 Hennessy MB, Mendoza SP, Mason WA, Moberg GP. 1995. Endocrine sensitivity to novelty in 763 squirrel monkeys and titi monkeys: species differences in characteristic modes of responding to the 764 environment. Physiology \& Behavior 57: 331-338. DOI: 10.1016/0031-9384(94)00250-9

765 Hernani-Lineros H, Garcia E., Pacheco LF. 2020. Andean bear diet near to and far from a road. 766 Ursus 31: 1-7. DOI: 10.2192/URSUS-D-19-0003.1

767 Hodges JK, Heistermann M. 2011. Field endocrinology: monitoring hormonal changes in free768 ranging primates. In: JM Setchell, J. Curtis, eds. Field and laboratory methods in primatology: a 769 practical guide, Second Edition, Cambridge University Press, 353-370. DOI: 10.1002/ajpa.20496 
770 Hostetler CM, Hinde K, Maninger N, Mendoza SP, Mason WA, Rowland DJ, Bales KL. 2016.

771 Effects of pair bonding on dopamine D1 receptors in monogamous male titi monkeys (Callicebus

772 cupreus). American Journal of Primatology 79: 1-9. DOI: 10.1002/ajp.22612

773 Huck M, Di Fiore A, Fernandez-Duque E. 2020. Of apples and oranges? The evolution of

774 “monogamy" in non-human primates. Frontiers in Ecology and Evolution 7: 472. DOI:

$77510.3389 /$ fevo.2019.00472

776 Kalbitzer U, Heistermann M. 2013. Long-term storage effects in steroid metabolite extracts from

777 baboon (Papio sp.) faeces - a comparison of three commonly applied storage methods. Methods in

778 Ecology and Evolution 4: 493-500. DOI: 10.1111/2041-210X.12054

779 Kaplan G, Pines MK, Rogers LJ. 2012. Stress and stress reduction in common marmosets. Applied 780 Animal Behaviour Science 137: 175-182. DOI: 10.1016/j.applanim.2011.04.011

781 Kight CR, Swaddle JP. 2011. How and why environmental noise impacts animals: An integrative, 782 mechanistic review. Ecology Letters 14: 1052-1061. DOI: 10.1111/j.1461-0248.2011.01664.x

783 Kulp, J, Heymann EW. 2015. Ranging, activity budget, and diet composition of red titi monkeys

784 (Callicebus cupreus) in primary forest and forest edge. Primates 56: 273-278. DOI:

$78510.1007 / \mathrm{s} 10329-015-0471-5$

786 Kunc HP, Schmidt R. 2019. The effects of anthropogenic noise on animals: a meta-analysis. Biology

787 Letters 15: 20190649. DOI: 10.1098/rsbl.2019.0649

788 Laundré JW, Hernández L, Ripple WJ. 2010. The landscape of fear: ecological implications of being 789 afraid. The Open Ecology Journal 3: 1-7. DOI: 10.2174/1874213001003030001

790 Laurance WF, Goosem M, Laurance SGW. 2009. Impacts of roads and linear clearings on tropical

791 forests. Trends in Ecology \& Evolution 24: 659-669. DOI: 10.1016/j.tree.2009.06.009 
792 Magle SB, Hunt VM, Vernon M, Crooks KR. 2012. Urban wildlife research: past, present, and 793 future. Biological Conservation 155: 23-32. DOI: 10.1016/j.biocon.2012.06.018

794 Martínez-Mota R, Valdespino C, Sánchez-Ramos MA, Serio-Silva JC. 2007. Effects of forest

795 fragmentation on the physiological stress response of black howler monkeys. Animal Conservation 796 10: 374-379. DOI: 10.1111/j.1469-1795.2007.00122.x

797 McGregor PK, Horn AG, Leonard ML, Thomsen F. 2013. Anthropogenic noise and conservation.

798 In: Brumm H, ed. Animal communication and noise. Berlin: Springer Verlag, 409-444. DOI:

$799 \quad 10.1007 / 978-3-642-41494-7$

800 McMullen H, Schmidt R, Kunc HP. 2014. Anthropogenic noise affects vocal interactions.

801 Behavioral Processes 103: 125-128. DOI: 10.1016/j.beproc.2013.12.001.

802 Muhly TB, Semeniuk C, Massolo A, Hickman L, Musiani M. 2011. Human activity helps prey win 803 the predator-prey space race. PLOS ONE 6: e17050. DOI: 10.1371/journal.pone.0017050

804 Nagy-Reis MB, Seitz EZF. 2017. Foraging strategies of black-fronted titi monkeys (Callicebus 805 nigrifrons) in relation to food availability in a seasonal tropical forest. Primates 58: 149-158. DOI:

806 10.1007/s10329-016-0556-9

807 Norconk MA. 2007. Sakis, Uakaris, and Titi monkeys. Behavioral diversity in a radiation of primate 808 seed predators. In: Campbell CJ, Fuentes A, MacKinnon KC, Panger M, Bearder SK, eds. Primates 809 in perspective. Oxford University Press, 123-138. DOI: 10.1017/CBO9781139034210.023

810 Nowacek DP, Thorne LH, Johnston DW, Tyack PL. 2007. Responses of cetaceans to anthropogenic 811 noise: An update and review of behavioral and some physiological effects. Mammal Review 37: 81812 115. DOI: 10.1111/j.1365-2907.2007.00104.X

813 Nummela S. 2017. The primate peripheral auditory system and the evolution of primate hearing. In: 814 Quam RM, Ramsier MA, Fay RR, Popper AN, eds. Primate hearing and communication, Springer 
815 Handbook of Auditory Research vol. 63, Springer: Cham, 13-45. DOI: 10.1007/978-3-319-59478-

816 1_2

817 Odum EP, Kuenzler EJ. 1955. Measurement of territory and home range size in birds. The Auk 72:

818 128-137. DOI: $10.2307 / 4081419$

819 Palacios MG, D’Amico VL, Bertellotti M. 2018. Ecotourism effects on health and immunity of

820 Magellanic penguins at two reproductive colonies with disparate touristic regimes and population

821 trends. Conservation Physiology, 6: coy060. DOI: 10.1093/conphys/coy060

822 Pijanowski BC, Villanueva-Rivera LJ, Dumyahn SL, Farina A, Krause BL, Napoletano BM, Gage

823 SH, Pieretti N. 2011. Soundscape ecology: the science of sound in the landscape. Bioscience 61:

824 203-216. DOI: 10.1525/bio.2011.61.3.6

825 Price E, Coleman R, Ahsmann J, Glendewar G, Hunt J, Smith T. 2019. Individual, social, and 826 environmental factors affecting salivary and fecal cortisol levels in captive pied tamarins (Saguinus

827 bicolor). American Journal of Primatology 81(8): e23033. DOI: 10.1002/ajp.23033

828 R Core Team. 2016. R: A language and environment for statistical computing. R Foundation for

829 Statistical Computing, Vienna (Austria). https://www.R-project.org

830 Raboin M, Elias DO. 2019. Anthropogenic noise and the bioacoustics of terrestrial invertebrates.

831 Journal of Experimental Biology 222: 1-11. DOI: 10.1242/jeb.178749

832 Ragen BJ, Maninger N, Mendoza SP, Jarcho MR, Bales KL. 2013. Presence of a pair-mate regulates 833 the behavioral and physiological effects of opioid manipulation in the monogamous titi monkey

834 (Callicebus cupreus). Psychoneuroendocrinology 38: 2448-2461. DOI:

835 10.1016/j.psyneuen.2013.05.009 
836 Rangel-Negrín A, Alfaro JL, Valdez RA, Romano MC, Serio-Silva JC. 2009. Stress in Yucatan

837 spider monkeys: Effects of environmental conditions on fecal cortisol levels in wild and captive 838 populations. Animal Conservation 12: 496-502. DOI: 10.1111/j.1469-1795.2009.00280.x

839 Reinhardt KD, Vyazovskiy VV, Hernandez-Aguilar RA, Imron MA, Nekaris KA. 2019.

840 Environment shapes sleep patterns in a wild nocturnal primate. Scientific Reports 9: 9939. DOI:

$841 \quad 10.1038 / \mathrm{s} 41598-019-45852-2$

842 Rimbach R, Link A, Heistermann M, Gómez-Posada C, Galvis N, Heymann EW. 2013. Effects of

843 logging, hunting, and forest fragment size on physiological stress levels of two sympatric ateline 844 primates in Colombia. Conservation Physiology 1:cot031.

845 Rodriguez A, Gasc A, Pavoine S, Grandcolas P, Gaucher P, Sueur J. 2013. Temporal and spatial 846 dynamics of animal sound within a neotropical forest. Ecological Informatics 21:133-143.

847 DOI:10.1016/j.ecoinf.2013.12.006

848 Rumiz DI. 2013. Distribution, habitat and status of the White-coated titi monkey (Callicebus 849 pallescens) in the Chaco-Chiquitano forests of Santa Cruz, Bolivia. Neotropical Primates 19: 8-15. 850 Santos GS, Duarte M, Sousa-Lima R, Young R. 2017. Comparing contact calling between black 851 tufted-ear marmosets (Callithrix penicillata) in a noisy urban environment and in a quiet forest. 852 International Journal of Primatology 38: 1130-1137. DOI: 10.1007/s10764-017-0002-X

853 Sapolsky RM, Romero LM \& Munck AU. 2000. How do glucocorticoids influence stress responses? 854 Integrating permissive, suppressive, stimulatory, and preparative actions. Endocrine Reviews, 21, 855 55-89. DOI: 10.1210/edrv.21.1.0389

856 Saunders JC, Dooling RJ. 2018. Characteristics of temporary and permanent threshold shifts in 857 vertebrates. In: Slabbekoorn H, Dooling RJ, Popper AN, Fay RR, eds. Effects of anthropogenic 858 noise on animals. Springer Handbook of Auditory Research, Springer: ASA Press, 83-108. DOI: 
859 10.1007/978-1-4939-8574-6

860 Shanee S, Tello-Alvarado JC, Vermeer J, Boveda-Penalba AJ. 2013. GIS risk assessment and GAP

861 analysis for the Andean titi monkey (Callicebus oenanthe). Primate Conservation 26: 17-23. DOI:

$862 \quad 10.1896 / 052.026 .0111$

863 Shannon G, Angeloni LM, Wittemyer G, Fristrup KM, Crooks KR. 2014. Road traffic noise

864 modifies behaviour of a keystone species. Animal Behaviour 94: 135e141. DOI:

865 10.1016/j.anbehav.2014.06.004

866 Shannon G, McKenna MF, Angeloni LM, Crooks KR, Fristrup KM, Brown E, Warner KA, Nelson

867 MD, White C, Briggs J, McFarland S, Wittemyer G. 2016. A synthesis of two decades of research

868 documenting the effects of noise on wildlife. Biological Review, 91, 982-1005. DOI:

869 10.1111/brv.12207

870 Slabbekoorn H, Dooling RJ, Popper AN, Fay RR. 2018. Effects of anthropogenic noise on animals.

871 Springer Handbook of Auditory Research, Springer: ASA Press. DOI: 10.1007/978-1-4939-8574-6

872 Soto-Calderón ID, Álvarez-Cardona J, García-Montoya GM. 2016. Physiological and

873 parasitological implications of living in a city: the case of the white-footed tamarin (Saguinus

874 leucopus). American Journal of Primatology 9999: 1-10. DOI: 10.1002/ajp.22581

875 Sousa MBC, Ziegler TE. 1998. Diurnal variation on the excretion patterns of fecal steroids in

876 common marmoset (Callithrix jacchus) females. American Journal of Primatology 46: 105-117.

877 DOI: 10.1002/(sici)1098-2345(1998)46:2<105::aid-ajp1>3.3.co;2-j

878 Sueur J, Aubin T, Simonis C. 2008. Equipment review: seewave, a free modular tool for sound

879 analysis and synthesis. Bioacoustics 18: 213-226. DOI: 10.1080/09524622.2008.9753600

880 Sueur J, Farina A, Gasc A, Pieretti N, Pavoine S. 2014. Acoustic indices for biodiversity assessment

881 and landscape investigation. Acta Acustica united with Acustica 100: 772-781. DOI: 
$88210.3813 /$ AAA.918757

883 Swaddle JP, Page LC. 2007. Increased amplitude of environmental white noise erodes pair

884 preferences in zebra finches: implications for noise pollution. Animal Behaviour 74: 363-368. DOI:

885 10.1016/j.anbehav.2007.01.004

886 Tennessen JB, Parks SE and Langkilde T. 2014. Traffic noise causes physiological stress and

887 impairs breeding migration behaviour in frogs. Conservation Biology 2: 1-8. DOI:

888 10.1093/conphys/cou032 DOI:10.1093/conphys/cou032

889 Turner A, Fischer M, Tzanopoulos J. 2018. Sound-mapping a coniferous forest - Perspectives for

890 biodiversity monitoring and noise mitigation. PLoS ONE 13(1): e0189843. DOI:

891 10.1371/journal.pone.0189843

892 van der Speld RF, Bello R, Hebard L. 2017. Activity budget and ranging of a group of Madidi titis

893 (Plecturocebus aureipalatii ) in Reserva Ecólogica Taricaya, with preliminary notes on diet

894 composition, habitat usage and additional sightings. Neotropical Primates 23: 33-40.

895 Vanlangendonck N, Nuñez G, Chaves A, Gutiérrez-Espeleta GA. 2015. New route of investigation

896 for understanding the impact of human activities on the physiology of non-human primates. Journal

897 of Primatology 4 (123): 2. DOI: 10.4172/2167-6801.1000123

898 Walker BG, Dee Boersma P, Wingfield JC. 2005. Habituation of adult Magellanic penguins to

899 human visitation as expressed through behavior and corticosterone secretion. Conservation Biology

900 20: 146-154. DOI: 10.1111/j.1523-1739.2005.00271.x

901 Wallace RB, Martínez J, López-Strauss H, Barreta, J, Reinaga A, López L. 2013. Conservation

902 challenges facing two threatened endemic titi monkeys in a naturally fragmented Bolivian forest. In:

903 Marsh LK, Chapman CA, eds. Primates in fragments: complexity and resilience. Springer Science:

904 New York, NY, USA, 493-501. DOI: 10.1007/978-1-4614-8839-2_33 
905 Wallace R, Martínez JL, Ferrari S, Veiga LM. 2018. Plecturocebus donacophilus, Bolivian Gray

906 Titi. The IUCN Red List of Threatened Species. DOI:10.2305/IUCN.UK.2018-

907 2.RLTS.T41548A17972581.en

908 Wark JD, Amendolagine L, Lukas KE, Kuhar CW, Dennis PM, Snowdon CT, Schoffner T, Schook

909 MW. 2016. Fecal glucocorticoid metabolite responses to management stressors and social change in

910 four species of callitrichine monkeys. Primates 57: 267-277. DOI: 10.1007/s10329-016-0514-6

911 Wheeler BC, Tiddi B, Kalbitzer U, Visalberghi E, Heistermann H. 2013. Methodological

912 Considerations in the analysis of fecal glucocorticoid metabolites in tufted capuchins (Cebus

913 apella). International Journal of Primatology 34: 879-898. DOI: 10.1007/s10764-013-9703-y

914 Young D, Bennet-Clark HC. 1995. The role of the tymbal in cicada sound production. The Journal

915 of Experimental Biology 198: 1001-1019.

916 Ziegler TE, Wittwer DJ. 2005. Fecal steroid research in the field and laboratory: improved methods

917 for storage, transport, processing, and analysis. American Journal of Primatology 67: 159-174.

918 DOI: 10.1002/ajp.20175

919 Zollinger SA, Slater PJB, Nemeth E, Brumm H. 2018. Higher songs of city birds may not be an

920 individual response to noise. Proceedings of the Royal Society B 284: 20170602. DOI:

$921 \quad 10.1086 / 656275$ 


\section{Figure 1}

Study area

(A) Geographic location of the Ecological Park of Yvaga Guazú (red arrow pointing to red rectangle, bottom left) relative to the city of Santa Cruz de la Sierra. (B) Map sketching the three areas in the park where human disturbance was subjectively evaluated. Symbols denote a gradient in human presence from the entrance of the park to the quiet suburb of Campo Verde. (C) The grid layout consists of 27 points evenly spaced out along each of three transects ( $\mathrm{T} 1, \mathrm{~T} 2$ and $\mathrm{T} 3$ ), labeled according to their respective distance to the highway. 

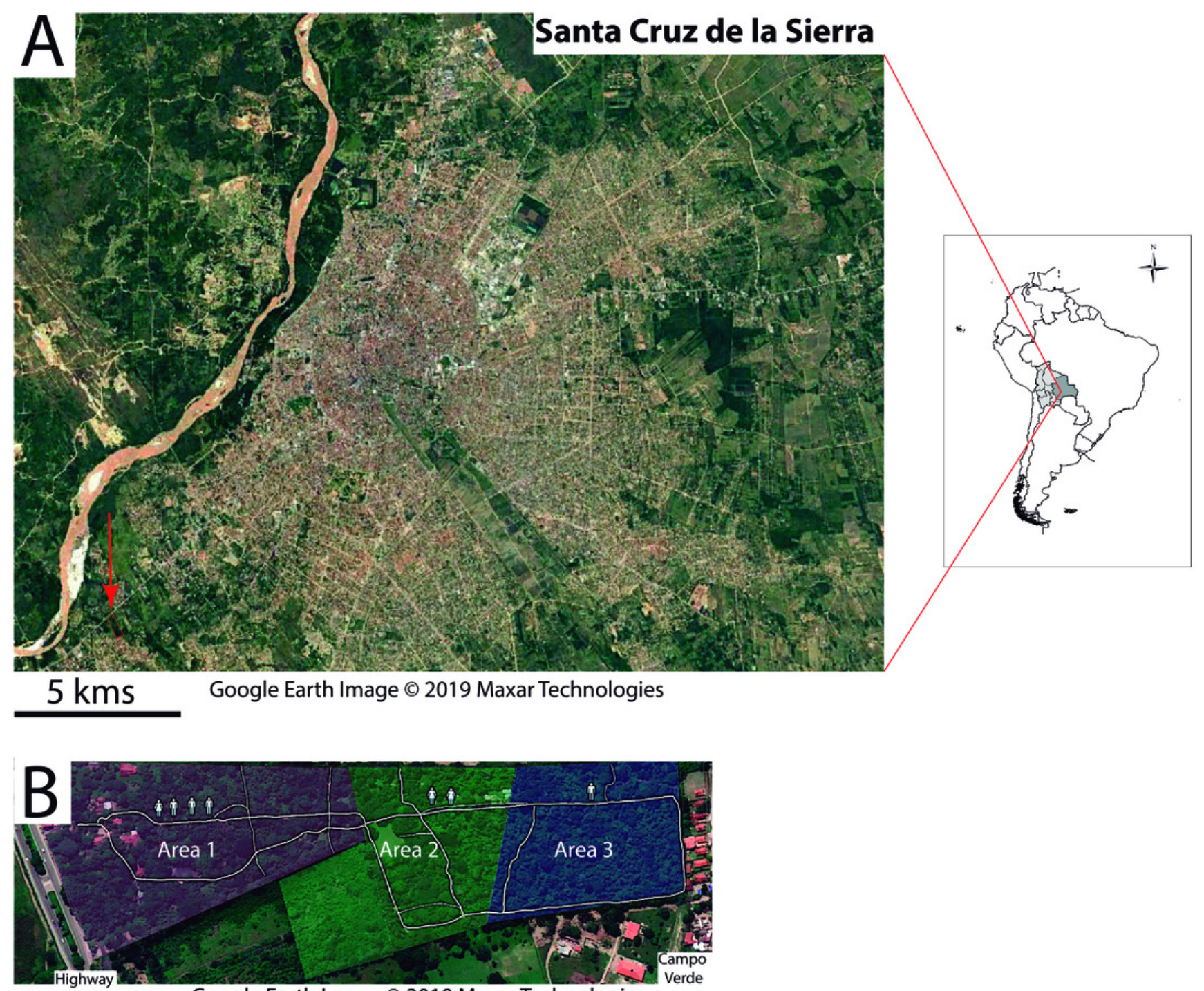

Google Earth Image @ 2019 Maxar Technologies

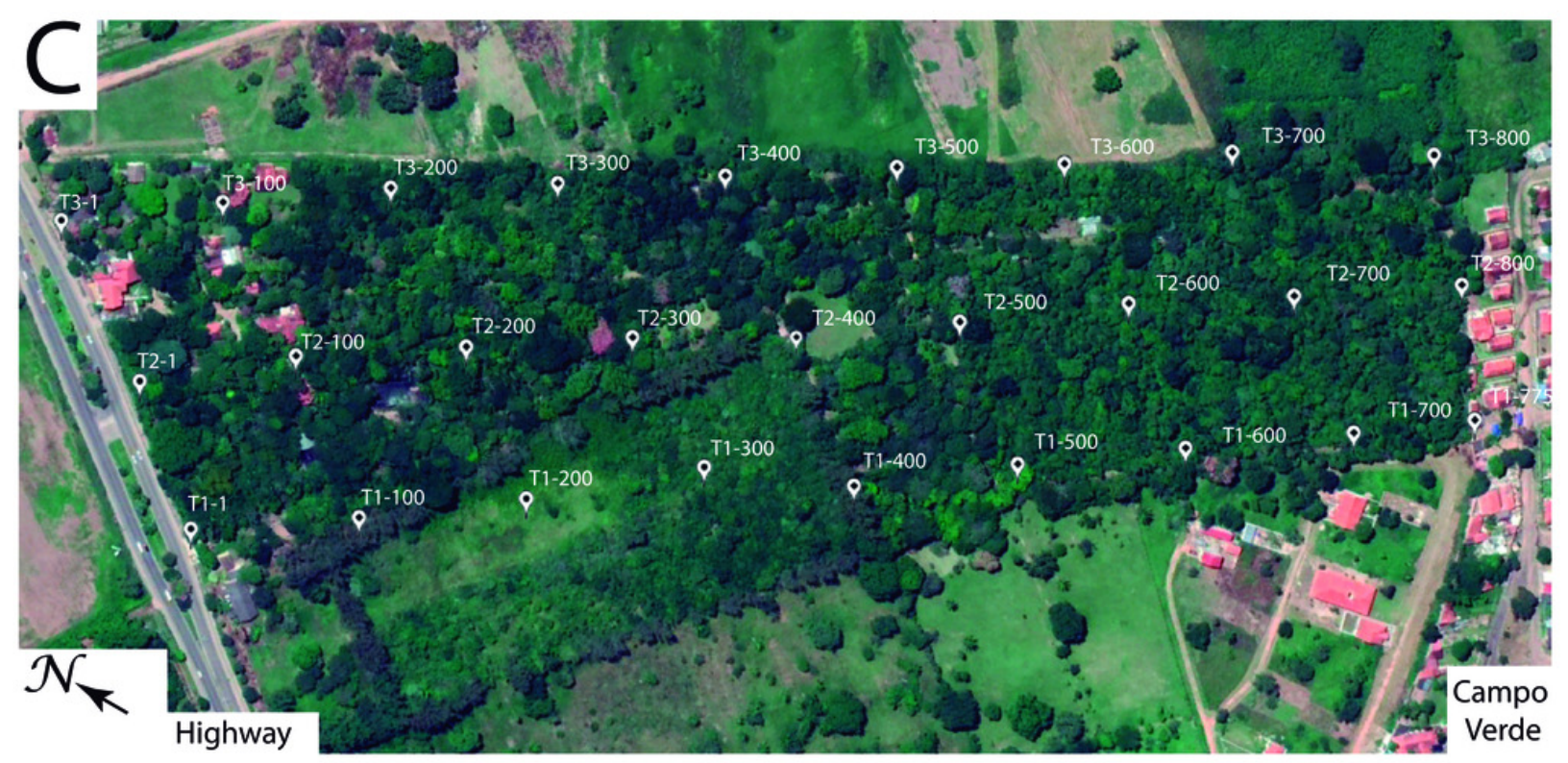

$100 \mathrm{~m}$

Google Earth Image @ 2019 Maxar Technologies

Peer) reviewing PDF | (2020:06:49834:1:2:NEW 15 Oct 2020) 


\section{Figure 2}

Noise gradient and circadian variation in RMS and M acoustic indices.

(A) The 27 locations where passive acoustic monitoring was carried out. The autonomous recording unit was deployed at four sites within the home range of each study group. The three sites near the highway (white symbols) served as a baseline for anthropogenic noise (reference area $\mathrm{GO}$ ). (B and D) Linear regressions as a function of diel and distance to the highway shown for the RMS and $\mathrm{M}$ indices, respectively. Each data point represents a mean value resulting from 72 one-minute samples at each recording site. ( $C$ and $E$ ) Boxplots comparing nocturnal and diurnal RMS values inside the titis' home ranges for the six studied groups (G1-G6) relative to the reference area G0. Note the non-linearity of the gradient due to increased RMS values in $\mathrm{G} 4$ home range. ( $E$ and $F$ ) Circadian variation in the RMS and $M$ indices. Colored traces display the mean values from 3 sites near the highway (reference area $\mathrm{G} 0$ ) and from 4 sites inside each home range (G1-G6). 

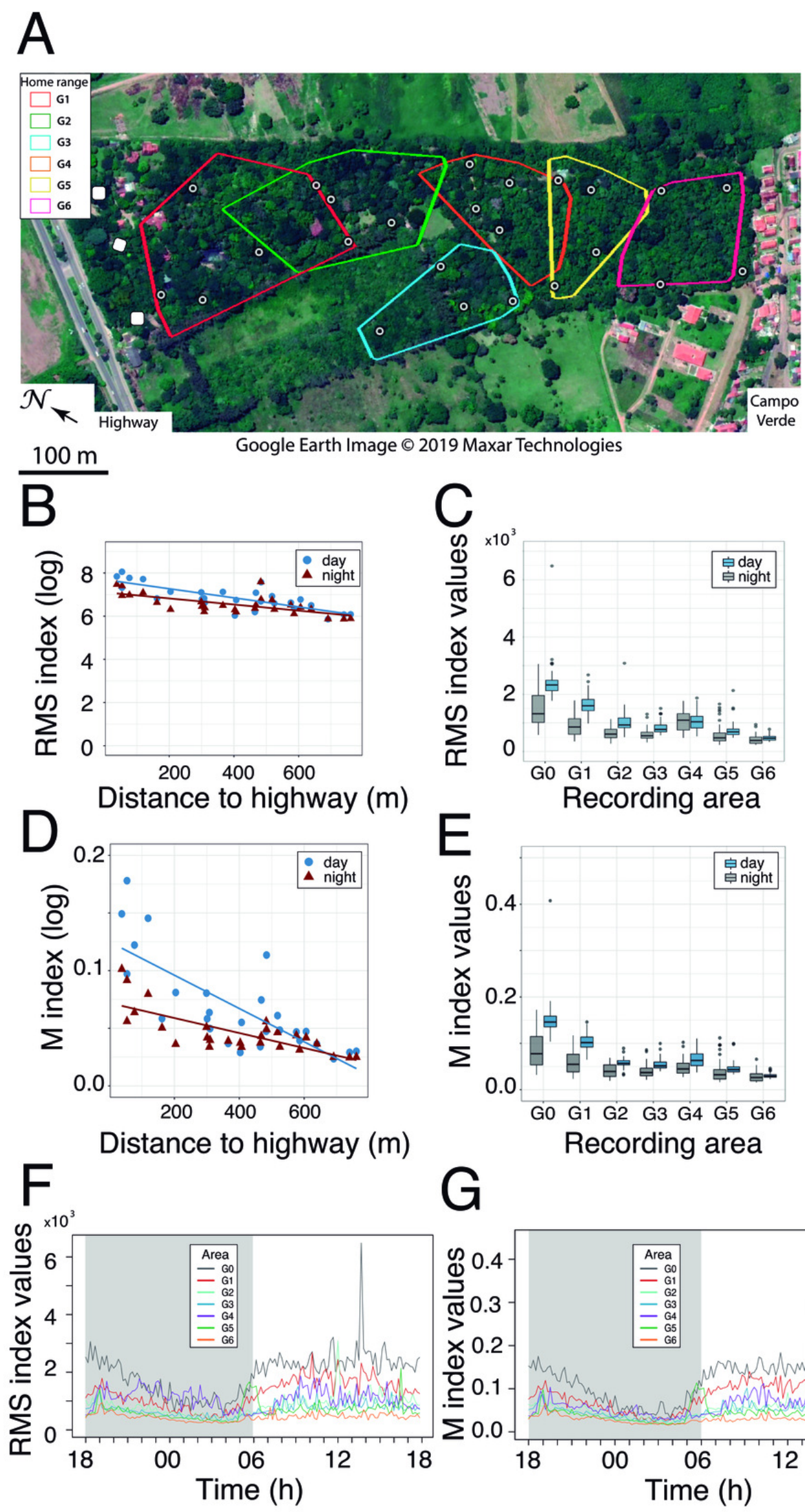

G

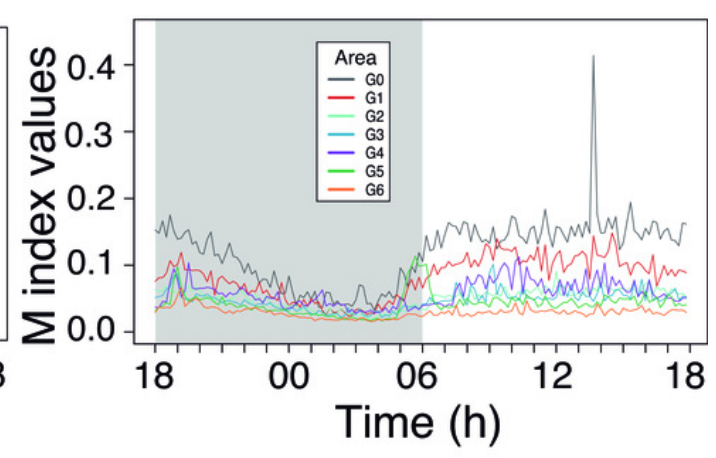


Figure 3

Mannequin used in field experiment

One observer is concealed in the background. Photo credit: Lucero M. Hernani Lineros 


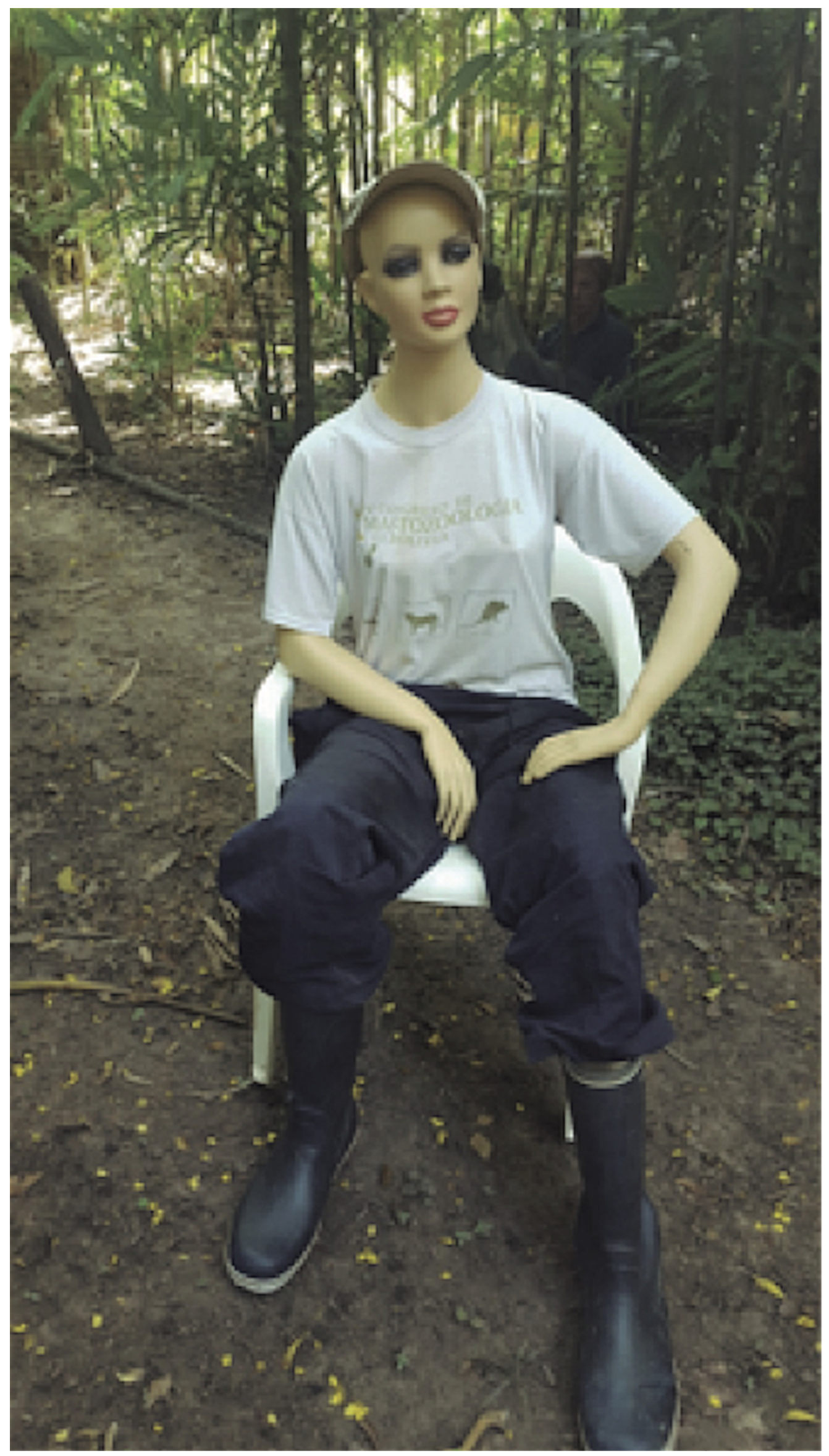




\section{Figure 4}

Sound pressure gradient.

(A) Interaction plots generated by the linear mixed model. The fixed variables that were entered in the full model are shown at bottom. In the evening hours (18:00 h), the cicadas' chorus produced a significant increase in sound pressure levels (vertical arrow). $\mathrm{N}=$ North orientation, $\mathrm{S}=$ South orientation, $\min =$ minimal values, $\max =$ maximal values. (B) Changes in sound pressure levels as a function of distance to the highway and time of day. Minimal ( $\min$ ) and maximal (max) values are plotted separately. Within each panel, the values obtained for each sampling day are connected by lines, which are color-coded per transect (T1: green, T2: red, T3: black). The non-linear noise gradient is more obvious for minimum values than it is for maximum values. Vertical arrows point to an increase in the minimum sound pressure levels resulting from the cicada's chorus at dusk. 

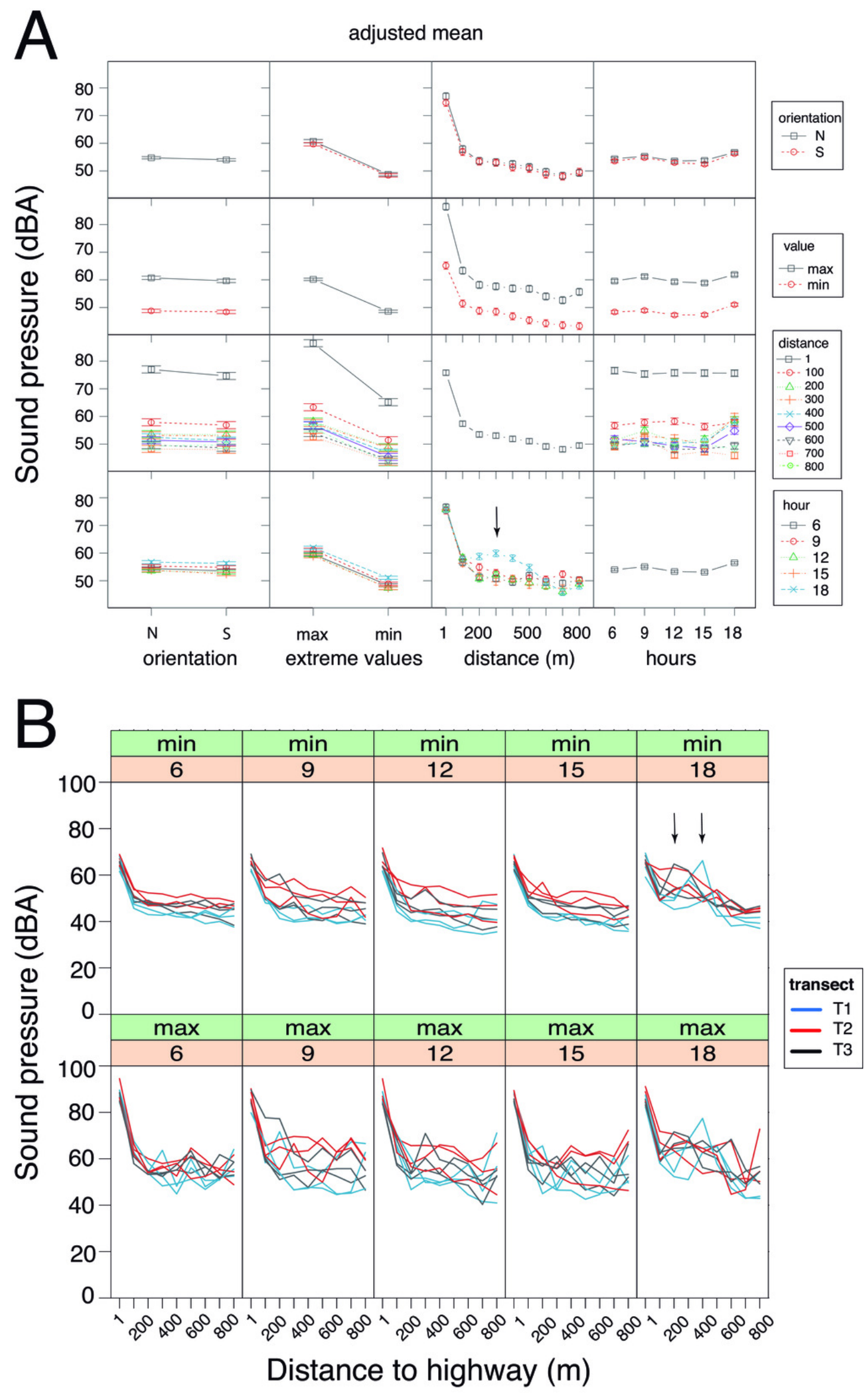


\section{Figure 5}

Use of space and activity-budget.

(A) Reconstruction of the 75 travel paths registered during the study period. A color-code distinguishes between family groups and symbols denote the starting point of a given path.

(B) Histograms of group activity budgets: proportion of time spent by each group of titis performing each activity (RE: resting, MO: moving, FO: foraging, OB: observing, SO:

socializing). (C) Histograms of utilization of forest strata: proportion of time spent by the titis in each forest level (S1: 0-5 m, S2: 5-10 m; S3: 10-15 m). For quantitative analysis, data from S2 and S3 were lumped, owing to fewer occurrences in S3. (D) Graphical output of standardized residuals for group activity budgets. (E) Graphical output of standardized residuals for utilization of forest strata. (F) Activity budgets of adult pairs and (G) infantjuvenile pairs are plotted as a function of the nearest distance of their home range to the highway. 

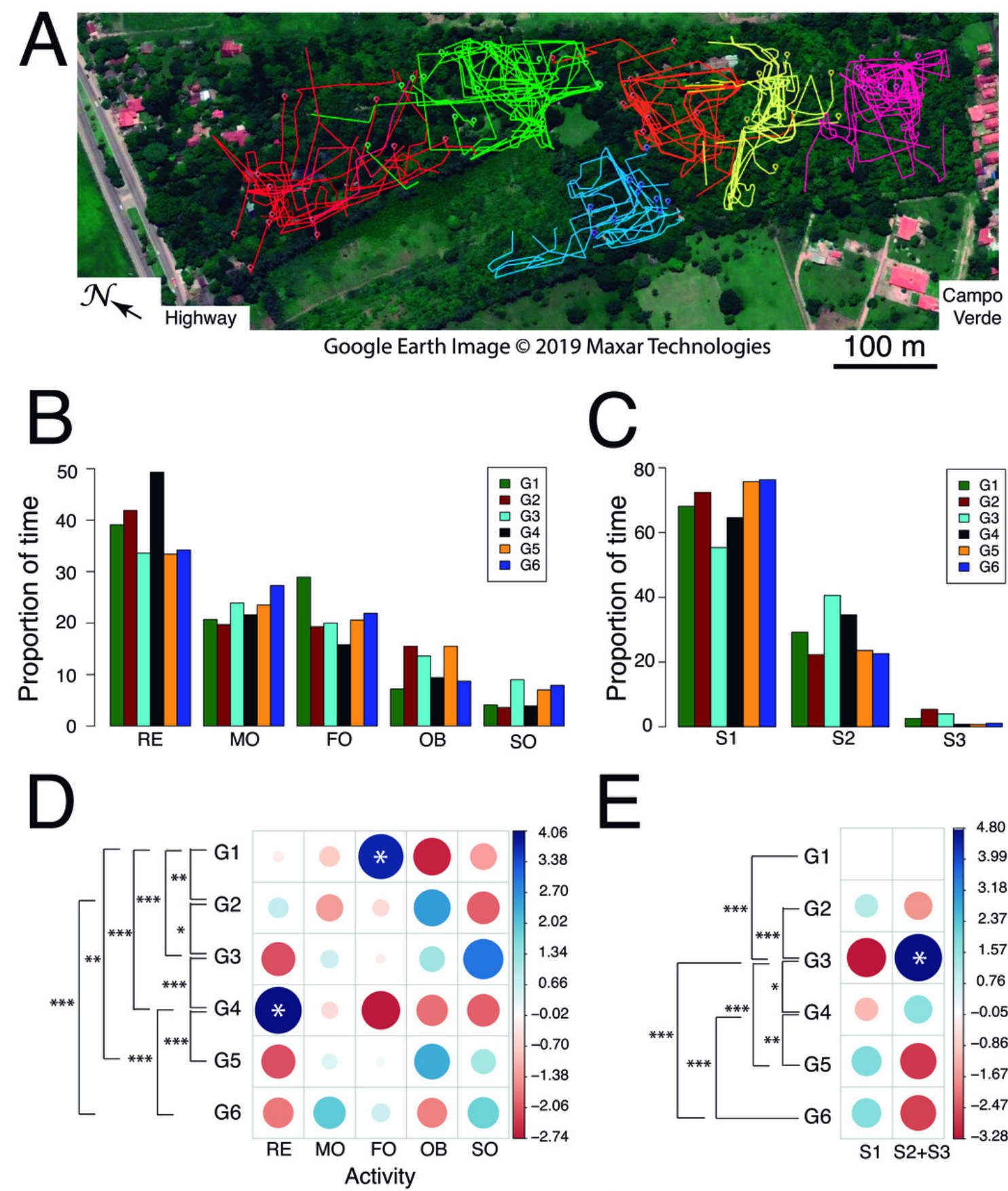

$\mathrm{F}$

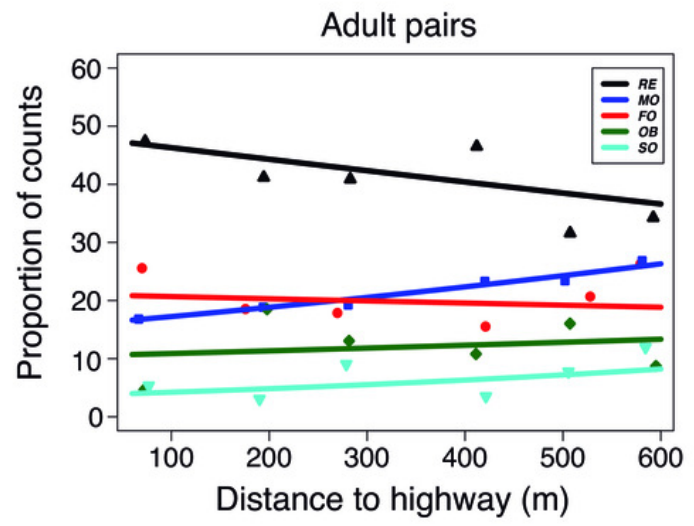

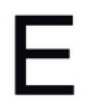
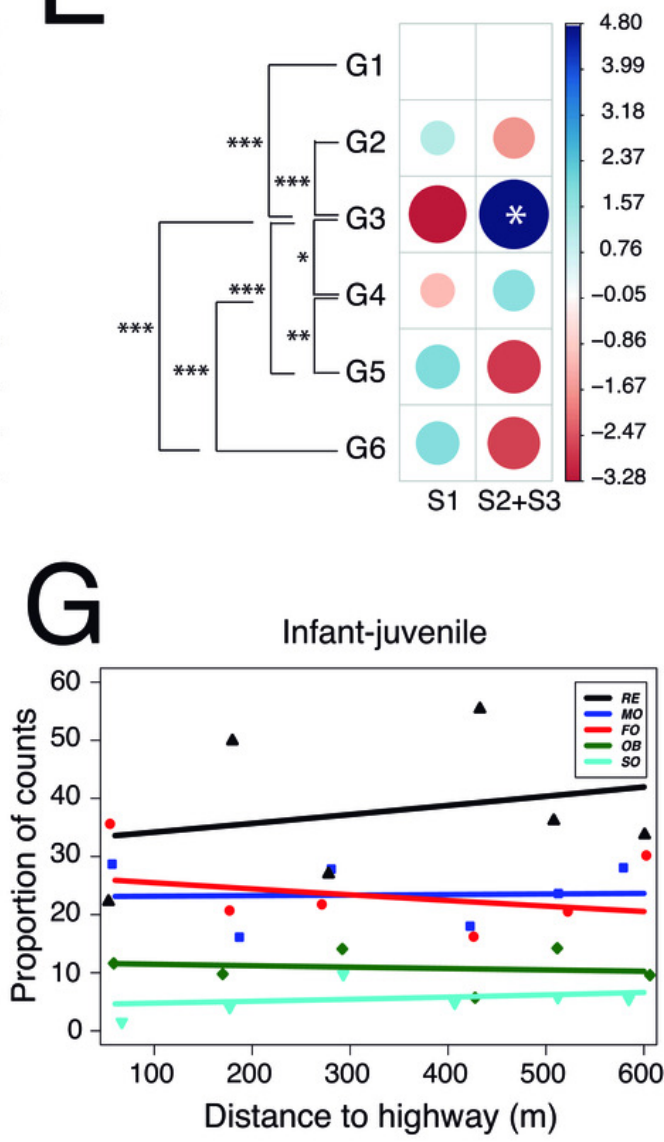
Figure 6

Fecal cortisol concentrations.

(A) Mean values $( \pm 95 \% \mathrm{Cl}$ ) plotted for each of the nineteen individuals from which one fecal sample at least was obtained. Labels identify the individual age-sex classes: I = infant, J = juvenile, $\mathrm{S}=$ sub-adult, $\mathrm{M}=$ adult male and $\mathrm{F}=$ adult female. (B) Relationships between cortisol concentrations and acoustic indices after z-score transformation. For each group, mean values have been plotted as a function of the nearest distance of their home range to the highway. Regression lines are displayed with their respective $95 \%$ confidence intervals.
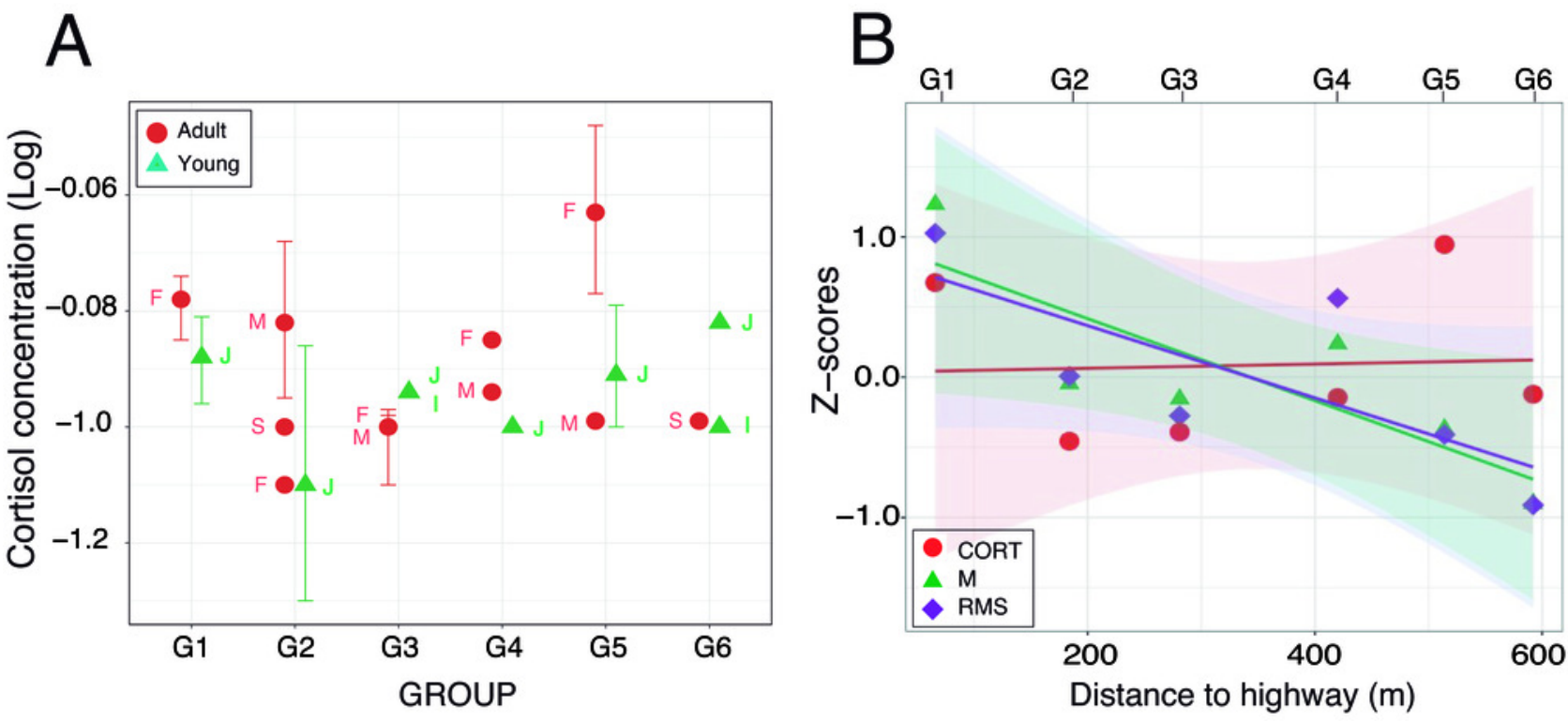


\section{Table $\mathbf{1}$ (on next page)}

Main sources of anthropogenic disturbance heard in the study area. 
1

2 Table 1:

3 Main sources of anthropogenic disturbance heard in the study area.

4

\begin{tabular}{|c|l|}
\hline Source & \multicolumn{1}{|c|}{ Description } \\
\hline Aerial traffic & Helicopter, small plane, jet aircraft \\
\hline Roadway traffic & Vehicles, horn, sirene \\
\hline Machinery & Tractor, lawnmower \\
\hline Tools & Machete, sprinkler, ladder, hammer \\
\hline \multirow{2}{*}{ Recreation } & Karaoke, music, radio, firecrackers \\
\hline \multirow{2}{*}{ Human voice } & Social events: soccer, wedding \\
\hline & Food sellers with loudspeaker \\
\hline & Normal conversation, guided tours \\
\hline
\end{tabular}

5 


\section{Table 2 (on next page)}

Information on group size and group composition.

Observation time for group movements and focal sampling is reported together with the number of tracks recorded, distance traveled by each group (mean $\pm \mathrm{SE}$ ) and traveling speed (mean $\pm \mathrm{SE})$. 
1 Table 2:

2 Information on group size and group composition.

3 Observation time for group movements and focal sampling is reported together with the number

4 of tracks recorded, distance traveled by each group (mean $\pm \mathrm{SE}$ ) and traveling speed (mean \pm 5 SE).

6

\begin{tabular}{|c|c|c|c|c|c|c|c|c|c|}
\cline { 5 - 10 } \multicolumn{2}{c|}{} & \multicolumn{6}{c|}{ Group movements } & $\begin{array}{c}\text { Focal } \\
\text { sampling }\end{array}$ \\
\hline $\begin{array}{c}\text { Group } \\
\text { name }\end{array}$ & $\begin{array}{c}\text { Group } \\
\text { size }\end{array}$ & $\begin{array}{c}\text { Group } \\
\text { composition }\end{array}$ & $\mathrm{D}$ & $\mathrm{H}$ & $\mathrm{T}$ & $\begin{array}{c}\text { Distance } \\
\text { traveled }(\mathrm{m})\end{array}$ & $\begin{array}{c}\text { Travel speed } \\
(\mathrm{m} / \mathrm{h})\end{array}$ & $\mathrm{D}$ & $\mathrm{H}$ \\
\hline G1 & 4 & MFJI & 14 & 48 & 15 & $232.3 \pm 36.9$ & $91.4 \pm 11.6$ & 7 & 35 \\
\hline G2 & 5 & MFSJI & 18 & 63 & 19 & $260.0 \pm 49.9$ & $95.3 \pm 14.6$ & 7 & 43 \\
\hline G3 & 5 & MFJIB & 9 & 37 & 10 & $211.6 \pm 53.2$ & $81.9 \pm 22.7$ & 7 & 42 \\
\hline G4 & 5 & MFJIB & 8 & 52 & 9 & $307.4 \pm 57.8$ & $63.2 \pm 15.0$ & 13 & 67 \\
\hline G5 & 4 & MFJI & 9 & 42 & 9 & $269.3 \pm 56.0$ & $77.7 \pm 12.1$ & 9 & 39 \\
\hline G6 & 6 & MFSJIB & 12 & 43 & 13 & $261.2 \pm 54.0$ & $80.3 \pm 9.2$ & 8 & 40 \\
\hline
\end{tabular}

7

8 D: number of days, H: number of hours; T: number of tracks; M: adult male, F: adult female, S:

9 sub-adult, J: juvenile, I: infant, B: un-weaned infant. 


\section{Table 3 (on next page)}

Categories of behavior distinguished during focal sampling.

In the text, the terms moving and traveling are used interchangeably. Similarly, we consider observing and vigilance as equivalent. 
1

2 Table 3:

3 Categories of behavior distinguished during focal sampling.

4 In the text, the terms moving and traveling are used interchangeably. Similarly, we consider 5 observing and vigilance as equivalent.

6

\begin{tabular}{|c|c|c|}
\hline $\begin{array}{l}\text { Behavioral } \\
\text { categories }\end{array}$ & Acronym & Description \\
\hline \multirow{3}{*}{ Resting } & \multirow{3}{*}{$\mathrm{RE}$} & Asleep (eyes closed, head down) \\
\hline & & Awake and remains still \\
\hline & & Basking on the edge or on top of the canopy \\
\hline Observing & $\mathrm{OB}$ & $\begin{array}{l}\text { Scanning the environment with noticeable head } \\
\text { movements while remaining stationary on a branch }\end{array}$ \\
\hline Moving & $\mathrm{MO}$ & Quadrupedal locomotion, climbing, leaping \\
\hline Foraging & FO & $\begin{array}{l}\text { Searching for and consuming food items (fruits, } \\
\text { flowers, leaves and insects) }\end{array}$ \\
\hline \multirow{5}{*}{ Socializing } & \multirow{5}{*}{$\mathrm{SO}$} & Grooming \\
\hline & & Agonistic interaction \\
\hline & & Play \\
\hline & & Tail twining \\
\hline & & Vocalizing loudly or softly \\
\hline
\end{tabular}




\section{Table 4(on next page)}

\section{Cortisol concentrations.}

The 30 fecal samples have been sorted by group, individual and age category. $A=$ adult; $Y=$ young; $F$ = female; $M=$ male; $S=$ subadult; $\mathrm{J}=$ juvenile; $I$ = infant. Asterisqs denote the two highest values, which were measured in one adult female from G5. 
2 Table 4.

3 Cortisol concentrations.

4 The 30 fecal samples have been sorted by group, individual and age category. $\mathrm{A}=$ adult; $\mathrm{Y}=$ 5 young; $\mathrm{F}=$ female; $\mathrm{M}=$ male; $\mathrm{S}=$ subadult; $\mathrm{J}=$ juvenile; $\mathrm{I}=$ infant. Asterisqs denote the two 6 highest values, which were measured in one adult female from G5.

7

8

\begin{tabular}{|c|c|c|c|c|c|c|}
\hline Group & $\begin{array}{c}\text { Sample } \\
\#\end{array}$ & $\begin{array}{c}\text { Date } \\
\text { (MMDDYY) }\end{array}$ & Individual & $\begin{array}{c}\text { Age } \\
\text { category }\end{array}$ & $\begin{array}{c}\text { Time of } \\
\text { day }\end{array}$ & $\begin{array}{c}\text { Cortisol cc. } \\
(\mu \mathrm{g} / \mathrm{dL})\end{array}$ \\
\hline G1 & 15 & $12 / 09 / 17$ & $\mathrm{~F}$ & A & $07: 22$ & 0.142 \\
\hline G1 & 29 & $04 / 05 / 18$ & $\mathrm{~F}$ & A & $10: 26$ & 0.182 \\
\hline G1 & 30 & $04 / 05 / 18$ & $\mathrm{~F}$ & A & $10: 26$ & 0.175 \\
\hline G1 & 16 & $12 / 09 / 17$ & $\mathrm{~J}$ & $\mathrm{Y}$ & $07: 22$ & 0.110 \\
\hline G1 & 17 & $12 / 09 / 17$ & $\mathrm{~J}$ & $\mathrm{Y}$ & $07: 22$ & 0.155 \\
\hline G2 & 9 & $11 / 22 / 17$ & $\mathrm{~F}$ & A & $16: 56$ & 0.071 \\
\hline G2 & 18 & $12 / 12 / 17$ & $\mathrm{M}$ & A & - & 0.207 \\
\hline G2 & 19 & $12 / 12 / 17$ & $\mathrm{M}$ & A & - & 0.113 \\
\hline $\mathrm{G} 2$ & 10 & $11 / 23 / 17$ & $\mathrm{~S}$ & A & $14: 40$ & 0.092 \\
\hline G2 & 21 & $01 / 16 / 18$ & $\mathrm{~J}$ & $\mathrm{Y}$ & - & 0.140 \\
\hline G2 & 28 & $04 / 05 / 18$ & $\mathrm{~J}$ & $\mathrm{Y}$ & $10: 26$ & 0.051 \\
\hline G3 & 11 & $11 / 28 / 17$ & $\mathrm{~F}$ & $\mathrm{~A}$ & $15: 24$ & 0.108 \\
\hline G3 & 12 & $11 / 28 / 17$ & $\mathrm{~F}$ & A & $15: 24$ & 0.095 \\
\hline G3 & 23 & $03 / 20 / 18$ & $\mathrm{M}$ & A & $10: 29$ & 0.105 \\
\hline G3 & 24 & $03 / 20 / 18$ & $\mathrm{M}$ & $\mathrm{A}$ & $10: 29$ & 0.089 \\
\hline G3 & 6 & $11 / 11 / 17$ & $\mathrm{~J}$ & $\mathrm{Y}$ & 09:47 & 0.114 \\
\hline G3 & 5 & $11 / 11 / 17$ & I & $\mathrm{Y}$ & 09:47 & 0.116 \\
\hline G4 & 7 & $11 / 13 / 17$ & $\mathrm{~F}$ & A & $17: 42$ & 0.141 \\
\hline G4 & 25 & $03 / 22 / 18$ & $\mathrm{M}$ & $\mathrm{A}$ & 09:41 & 0.115 \\
\hline G4 & 20 & $12 / 19 / 17$ & $\mathrm{~J}$ & $\mathrm{Y}$ & $13: 55$ & 0.095 \\
\hline G5 & 1 & $10 / 17 / 17$ & $\mathrm{~F}$ & A & $18: 22$ & $0.319 *$ \\
\hline G5 & 13 & $12 / 02 / 17$ & $\mathrm{~F}$ & A & $10: 29$ & $0.344 *$ \\
\hline G5 & 22 & $03 / 16 / 18$ & $\mathrm{~F}$ & A & - & 0.160 \\
\hline G5 & 26 & $03 / 28 / 18$ & $\mathrm{~F}$ & A & $10: 33$ & 0.179 \\
\hline G5 & 2 & $10 / 30 / 17$ & $\mathrm{M}$ & A & $15: 51$ & 0.103 \\
\hline G5 & 14 & $12 / 02 / 17$ & $\mathrm{~J}$ & $\mathrm{Y}$ & $10: 29$ & 0.092 \\
\hline G5 & 27 & $03 / 28 / 18$ & $\mathrm{~J}$ & $\mathrm{Y}$ & $10: 33$ & 0.163 \\
\hline G6 & 8 & $11 / 18 / 17$ & $\mathrm{~S}$ & A & $12: 11$ & 0.103 \\
\hline G6 & 4 & $11 / 03 / 17$ & $\mathrm{~J}$ & $\mathrm{Y}$ & $17: 01$ & 0.150 \\
\hline G6 & 3 & $11 / 03 / 17$ & I & Y & $17: 01$ & 0.100 \\
\hline
\end{tabular}




\section{Table 5 (on next page)}

Family group activity budgets.

The proportion of time spent by each group (G1-G6) in distinct categories of activity is reported separately for each forest stratum (height) after pooling data from strata 2 and 3 (> $5)$. 
1 Table 5:

2 Family groups activity budgets.

3 The proportion of time spent by each group (G1-G6) in distinct categories of activity is reported

4 separately for each forest stratum (height) after pooling data from strata 2 and $3(>5)$.

5

\begin{tabular}{|c|c|c|c|c|c|c|c|c|c|}
\hline Activity & $\begin{array}{l}\text { Height } \\
\text { (m) }\end{array}$ & G1 & G2 & G3 & G4 & G5 & G6 & $\begin{array}{c}\text { Mean } \pm \mathrm{SD} \\
\%\end{array}$ & $\begin{array}{c}\text { Wilcoxon } \\
\text { p-value }\end{array}$ \\
\hline \multirow{2}{*}{$\mathrm{RE}$} & $\leq 5$ & 39.5 & 36.8 & 34.7 & 55.1 & 34.5 & 37.8 & $39.73 \pm 7.76$ & \multirow{2}{*}{$\begin{array}{c}V=9 \\
p=0.844\end{array}$} \\
\hline & $>5$ & 41.0 & 55.4 & 32.7 & 38.5 & 29.9 & 38.1 & $39.27 \pm 8.90$ & \\
\hline \multirow{2}{*}{ OB } & $\leq 5$ & 7.7 & 18.1 & 8.0 & 5.1 & 14.7 & 11.1 & $10.78 \pm 4.87$ & \multirow{2}{*}{$\begin{array}{c}V=8 \\
p=0.688\end{array}$} \\
\hline & $>5$ & 6.6 & 8.6 & 20.8 & 17.5 & 18.7 & 2.4 & $12.43 \pm 7.54$ & \\
\hline \multirow{2}{*}{ MO } & $\leq 5$ & 24.9 & 24.2 & 28.3 & 24.1 & 26.1 & 28.5 & $26.01 \pm 1.98$ & \multirow{2}{*}{$\begin{array}{c}\mathrm{V}=0 \\
\mathrm{p}=0.031\end{array}$} \\
\hline & $>5$ & 10.7 & 7.9 & 17.3 & 16.0 & 13.1 & 17.9 & $13.82 \pm 3.97$ & \\
\hline \multirow{2}{*}{ FO } & $\leq 5$ & 24.9 & 17.3 & 21.5 & 10.5 & 16.8 & 17.4 & $18.07 \pm 4.87$ & \multirow{2}{*}{$\begin{array}{c}\mathrm{V}=1 \\
\mathrm{p}=0.063\end{array}$} \\
\hline & $>5$ & 35.2 & 24.5 & 18.3 & 26.1 & 33.6 & 39.3 & $29.50 \pm 7.84$ & \\
\hline \multirow{2}{*}{$\mathrm{SO}$} & $\leq 5$ & 3.1 & 3.6 & 7.6 & 5.1 & 7.8 & 5.2 & $5.40 \pm 1.96$ & \multirow{2}{*}{$\begin{array}{c}\mathrm{V}= \\
\mathrm{p}=1.0\end{array}$} \\
\hline & $>5$ & 6.6 & 3.6 & 10.9 & 1.9 & 4.7 & 2.4 & $5.02 \pm 3.34$ & \\
\hline
\end{tabular}

6

$7 \mathrm{RE}=$ resting; $\mathrm{OB}=$ observing; $\mathrm{MO}=$ moving; $\mathrm{FO}=$ foraging; $\mathrm{SO}=$ socializing.

8 


\section{Table 6(on next page)}

Summary of field experiments with the mannequin.

Tests were performed in each of three areas exhibiting different levels of human presence. For each group, the table reports the total number of trials performed to achieve a successful test, characterized by the following parameters: wait period, individual who first detected the dummy, approach distance to the mannequin, calling duration, number of calls emitted during first minute and call type. $M=$ male, $F=$ female, $I=$ infant, $B=$ call $B, C=$ call $C, W=$ whistle. 
1 Table 6.

2 Summary of field experiments with the mannequin.

3 Tests were performed in each of three areas exhibiting different levels of human presence. For 4 each group, the table reports the total number of trials performed to achieve a successful test, 5 characterized by the following parameters: wait period, individual who first detected the dummy, 6 approach distance to the mannequin, calling duration, number of calls emitted during first minute 7 and call type. $\mathrm{M}=$ male, $\mathrm{F}=$ female, $\mathrm{I}=$ infant, $\mathrm{B}=$ call $\mathrm{B}, \mathrm{C}=$ call $\mathrm{C}, \mathrm{W}=$ whistle.

8

\begin{tabular}{|c|c|c|c|c|c|c|c|c|c|}
\hline Area & $\begin{array}{l}\text { Human } \\
\text { presence }\end{array}$ & $\begin{array}{l}\text { Group } \\
\text { name }\end{array}$ & $\begin{array}{c}\# \\
\text { trials }\end{array}$ & $\begin{array}{l}\text { Wait } \\
\text { period } \\
(\mathrm{min})\end{array}$ & Indiv. & $\begin{array}{l}\text { Approach } \\
\text { distance } \\
\text { (m) }\end{array}$ & $\begin{array}{l}\text { Calling } \\
\text { duration } \\
\text { (s) }\end{array}$ & $\begin{array}{c}\text { \# calls } \\
\text { (1st min) }\end{array}$ & $\begin{array}{l}\text { Call } \\
\text { type }\end{array}$ \\
\hline \multirow{2}{*}{1} & \multirow{2}{*}{ High } & G1 & $1 / 6$ & 120 & $\mathrm{M}$ & 3.0 & - & 0 & - \\
\hline & & G2 & $1 / 3$ & 25 & I & 1.5 & 3 & 1 & - \\
\hline \multirow{2}{*}{2} & \multirow{2}{*}{ Moderate } & G3 & $1 / 2$ & 59 & $\mathrm{~F}$ & 4.0 & 180 & 150 & B \\
\hline & & G4 & $1 / 1$ & 126 & I & 3.0 & 148 & $54-8$ & B - C \\
\hline \multirow{2}{*}{3} & \multirow{2}{*}{ Low } & G5 & $1 / 4$ & 120 & $\mathrm{~F}$ & 1.5 & 90 & $58-1$ & $B-W$ \\
\hline & & G6 & $1 / 1$ & 70 & - & 4.0 & 131 & 71 & B \\
\hline
\end{tabular}

9

$10 \mathrm{M}=$ male, $\mathrm{F}=$ female, $\mathrm{I}=$ infant, $\mathrm{B}=$ call $\mathrm{B}, \mathrm{C}=$ call $\mathrm{C}, \mathrm{W}=$ whistle. 